\title{
Particulate and lodine Removal Analysis for HTGR Containments
}

July 1976

Prepared for

Nuclear Regulatory Commission 


\title{
NOTICE
}

This report was prepared as an account of work sponsored by the United States Covernment. Neither the United States nor the United States Nuclear Regulatory Commission, nor any of their employees, nor any of their contractors, subcontractors, or their employees, makes any warranty, express or implied, or assumes any legal liability or responsibility for the accuracy, completeness or usefulness of any information, apparatus, product or process disclosed, or represents that its use would not infringe privately owned rights.

\author{
PACIFIC NORTHWEST LABORATORY \\ operated by \\ BATTELLE \\ for the \\ U.S. ENERCY RESEARCH AND DEVELOPMENT ADMINISTRATION \\ Under Contract $E(45-1)-1830$
}

\author{
Printed in the United States of America \\ Available from \\ National Technical iniormation Service \\ U.S. Department of Commerce \\ 5285 Port Royal Road \\ Springfield, Virginia 22151 \\ Price: Printed Copy \$6.00; Microiiche $\leq 2.25$
}


BNWL -2108

NRC -8

PARTICULATE AND IODINE REMOVAL ANALYSIS FOR HTGR CONTAINMENTS

by

Principal Authors for Part I, Particle Removal

J. A. Gieseke

E. W. Schmidt

P. Baybutt

H. Jordan

Principal Author for Part II, Iodine Removal

A. K. Postma

July 1976

BATTELLE

Pacific Northwest Laboratories

Richland, Washington 99352 
The removal of aerosol particles and iodine in the containment vessel of an HTGR following a loss-of-coolant accident was examined for two hypothetical accidents; the Design Basis Depressurization Accident (DBDA) and the Maximum Hypothetical Fission Product Release (MHFPR). Current containment cleanup system designs and others were evaluated. The HAARM- 2 computer model was adapted to describe aerosol behavior and to predict the consequences of the postulated accidents and to predict the time dependent behavior (agglomeration, growth, deposition and leakage) of the aerosol. Comparative hypothetical cases for the DBDA and MHFPR demonstrated the effect of concentration, filter removal, particle size distribution and temperature and pressure on particle removal with the concentration level and filter removal mechanisms showing the most significant effect. For the reference containment system design, plateout on surfaces and the recirculating filterabsorber were the principal iodine removal mechanisms of those considered. Removal of airborne iodine from the containment vessel due to an air cleaning system and by surface deposition was modelled, and the time variation for the total iodine concentration in the reference plant predicted. Surface deposition and operation of the air cleaning system rapidly lowers the airborne iodine concentration until about 0.3 percent of that released remains airborne. Beyond this point the model predicts a leveling in concentration due to desorption from surfaces. 
ACKNOWLEDGMENTS

This work utilized the General Atomic Standard Safety Analysis Report, the Fulton Generating Station PSAR and a broad base of experimental and theoretical information of previous researchers which made this report possible. The authors also wish to thank Mr. W. F. Pasedag, Accident Analysis Branch, Nuclear Regulatory Commission, our technical contact, for his technical guidance in attacking and completing the work. 
TABLE OF CONTENTS

PART I

$\underline{\text { Page }}$

ACCIDENT DEFINITION. . . . . . . . . . . . . . . . 5

Sequence of Events During DBDA and MHFPR. . . . . . . . 5

Source Terms and Radionuclide Classification. . . . . . . 6

Graphite Dust Data. . . . . . . . . . . . . . . 7

HTGR CONTAINMENT AND CLEANUP SYSTEM. . . . . . . . . . . . . 8

HTGR Containment. . . . . . . . . . . . . . 8

Containment Conditions. . . . . . . . . . . . . 10

Containment Cleanup Systems . . . . . . . . . . 10

POSSIBLE AIR CLEANING CONCEPTS FOR USE IN AN HTGR. . . . . . . . . 10

Direct Removal Mechanisms . . . . . . . . . . . 12

Removal Enhancement Mechanisms. . . . . . . . . 14

Combination Mechanisms. . . . . . . . . . . . 14

ANALYSIS PROCEDURE . . . . . . . . . . . . . . . 15

Applicability of Existing Aerosol Behavior Codes to HTGR, . . 15

Description of HAARM-2 Code . . . . . . . . . . 15

HAARM-2 Modification to Include Filtration. . . . . . . . 20

DESCRIPTION OF THE PARTICULATE REMOVAL MECHANISMS AND THEIR

DEPENDENCE ON PARTICLE SIZE, CONTAINMENT CONDITIONS AND

CONTAINMENT GEOMETRY ..................... 21

Gravitational Settling. . . . . . . . . . . . . . 21

Wall Plating. . . . . . . . . . . . . . 22

Leakage . . . . . . . . . . . . . . . . 22

Filter Removal. . . . . . . . . . . . . . . 22 


\section{TABLE OF CONTENTS}

(continued)

PART I

Page

FISSION PRODUCT RELEASE SOURCE TERMS ................. 23

REMOVAL OF PARTICULATES FROM THE CONTAINMENT . . . . . . . . . 25

Effect of Concentration Level ............ . 25

Effect of Filter Removal . . . . . . . . . . 27

Effect of Size ................... . 32

Effect of Temperature and Pressure Profile . . . . . . . 32

Conclusions................... . . 32

Need for Further Code Development . . . . . . . . 33

REFERENCES . . . . . . . . . . . . . . . . . . . 35

APPENDIX A

TABLES USED TO OBTAIN PARTICULATE RELEASE ESTIMATES . . . . . . 36

$\underline{\text { PART II }}$

I. BACKGROUND . . . . . . . . . . . . . . . . . . 45

A. HTGR Design Considered . . . . . . . . . . . . 45

B. Accident Scenario Considered . . . . . . . . . . 45

II. POSTULATED IODINE SOURCE TERM TO CONTAINMENT . . . . . . . . 46

A. Iodine Release From Fuel .. . . . . . . . . . 46

III. IODINE TRANSPORT IN THE CONTAINMENT VESSEL . . . . . . . . 48

A. Description of Conditions in the Containment Atmosphere . 48 
TABLE OF CONTENTS

(continued)

PART II

Page

B. Removal Mechanisms For Iodine . . . . . . . . . 52

1. Air Cleaning System . . . . . . . . . 52

2. Surface Deposition of Elemental Iodine... . . . 54

3. Agglomeration and Fallout of Particulate Iodine . . 59

C. Model for Iodine Depletion in Containment Vessel . . . 59

1. Elemental Iodine.............. 59

2. Methyl Iodide Removal . . . . . . . . . . 64

3. Particulate Iodine Removal . . . . . . . . . 64

4. Total Airborne Iodine . . . . . . . . . . . 64

IV. ALTERNATIVE EMERGENCY AIR CLEANING SYSTEMS FOR HTGR PLANTS • 66

A. Scope of Present Survey . . . . . . . . . . . . 66

B. Candidate Systems Considered . . . . . . . . . . 67

C. Discussion of Candidate Systems . . . . . . . . 67

1. Recirculating Filter/Charcoal Adsorber System . . . 67

2. Recirculating Aqueous Scrubber System . . . . . 68

3. Direct Acting Spray System . . . . . . . . 68

4. Direct Acting Powder Dispersal System . . . . . . 69

V. LITERATURE CITED . . . . . . . . . . . . . . . . 71

DISTRIBUTION . . . . . . . . . . . . . . . . . . . . 73 
Table 1. Containment Dimensions . . . . . . . . . . 8

Table 2. Evaluation of Possible Air Cleaning Concepts . . . . 13

Table 3. Particulate Removal Cases . . . . . . . . . 26

Table 4. Release Basis ... . . . . . . . . . . 28

LIST OF FIGURES FOR PART I

Figure 1. HTGR Containment . . . . . . . . . . 9 9

Figure 2. Estimated and Assumed HTGR Containment

Conditions Following Postulated DBDA . . . . . . 11

Figure 3. Suspended Mass vs. Time for Several Concentration Levels . . . . . . . . . . . . 29

Figure 4. Leaked Mass vs. Time . . . . . . . . . 30

Figure 5. Suspended Concentration vs. Time Showing the Effects of Filter Removal and Particle Size . . . . . .

\section{LIST OF TABLES FOR PART II}

Table 1. Assumed Iodine Source Terms to Containment for Postulated MHFPR Accident . . . . . . . . . .

Table 2. Summarý of Iodine Source Terms to HTGR Containment Atmosphere for Postulated Accident . . . . . . . .

Figure 1. Schematic Diagram of Reference HTGR Containment Vesse1

Figure 2. Pressure in Containment Vessel Following a Depressurization Accident in the Fulton Station . . . . . . .

Figure 3. Gas Temperature in Containment Vessel Following a Depressurization Accident in the Fulton Station. . .

Figure 4. Components for Individual Air Cleaning Loops for Reference Containment System . . . . . . . . .

Figure 5. Mass Transfer Coefficients as a Function of Inside Temperature Difference for Steam-Air Atmospheres

Figure 6. Airborne Iodine Depletion by Filter Loop and Natural Plateout in Reference HTGR Containment . . . . . 62

Figure 7. Comparison of Model with CSE Test A-13 . . . . . . 63

Figure 8. Total Iodine Airborne Predicted for Reference HTGR Containment . . . . . . . . . . . . . 


\section{INTRODUCTION}

Fission product release and subsequent fission product behavior following a postulated nuclear reaction accident is of great importance in the overall safety analysis for high temperature gas reactors (HTGR's). This report.addresses the transport and deposition of particulate fission products, Part I, and iodine, Part II, within HTGR containments. For LWR's it has been assumed that 1 percent of all solid fission products are released from the core in the event of the loss-of-coolant accident of the severity which leads to the gaseous source terms specified in Regulatory Guides 1.3 and 1.4. To date no equivalent source term has been derived for the HTGR. As an interim measure the LWR source term of 1 percent of all solid fission products has been proposed for HTGR licensing calculations $(I-2)$. In LWR accident analyses, the particulate fission products are usually assumed to remain associated with the liquid in the reactor vessel or the containment sump. The absence of the liquid phase in the HTGR containment requires a more detailed examination of the fate of particulate fission products in the containment. The objective of this research program has been to examine particulate fission product behavior and to investigate particulate fission product removal within HTGR containments.

Except for iodine associated with particles, iodine behavior is considered to be independent of that of fission product aerosols and the core release and containment transport of iodine was analyzed accordingly. The approach for iodine was patterned after those used previously for light water reactors, allowing for the major differences between light water reactors and HTGR's. The accidents considered here are those which in light water reactors result in a major release of fission products to the containment vessel, as described in Regulatory Guides $1.3^{(\text {II- } 1)}$ and $1.4^{(I I-2)}$. These accidents are characterized by the postulated fission product source term; the source term should not be considered as that which results from a probable sequence of identified accident events. 
Thus the source term is hypothetical. Its use is valuable because the consequences resulting from the hypothetical accident are not exceeded by any accident scenario resulting from a credible sequence of events. The objective of this study of iodine behavior was to evaluate the rate of removal of iodine in the containment vessel by surface deposition and by engineered safety systems. A knowledge of containment depletion, together with the postulated source term, will permit an evaluation of an atmospheric iodine source term for reactor siting considerations. A detailed analysis of fuel heat-up, failure, iodine release rate, and transport inside the primary coolant system was beyond the scope of the present study. 
PART I - SUMMARY

PARTICULATE FISSION PRODUCT RELEASE

AND REMOVAL ANALYSES FOR HTGR'S

This study was conducted to develop procedures for evaluating solid fission product removal within containment following postulated HTGR accidents. Two hypothetical accidents, the Design Basis Depressurization Accident (DBDA) and the Maximum Hypothetical Fission Product Release (MHFPR), were examined. The possible sequence of events leading to these accidents and the range of accompanying solid fission product source terms have been discussed. Current containment cleanup system designs and other possible air cleaning concepts for use in an HTGR were evaluated. It was concluded that the current filter cleanup system design was among the most effective and applicable designs.

An existing computer model developed to describe aerosol behavior (HAARM-2) was adapted for use in predicting the consequence of the postulated HTGR accidents. This model includes gravitational and Brownian agglomeration, gravitational and diffusional removal, a source term, and leakage effects in predicting the time dependent behavior (agglomeration growth, deposition and leakage) of the aerosol. The dependence of the aerosol removal on particle size, containment conditions, containment geometry, and air cleaning systems was investigated.

Several hypothetical fission product release cases and the subsequent containment aerosol behavior for both the DBDA and the MHFPR were investigated. Comparative cases demonstrated the effect of concentration level, filter removal, particle size distribution, temperature and pressure on particulate removal. The concentration level and filter removal mechanism had the most significant effect. Intrinsic in the investigations was the predictive model's capability of handing a wide range of conditions and variables. 
PART II - SUMMARY

IODINE TRANSPORT AND DEPOSITION *

IN HTGR CONTAINMENT VESSEL

The core release, and transport in containment of iodine following hypothetical accidents was studied for a reference HTGR plant. Three separate iodine source terms were postulated for the containment vessel. An overall release of 50 percent of the core inventory was divided into a 1 percent puff at time zero, a 20 percent puff at one hour, and a 29 percent puff at two hours. Ten percent of released iodine was assumed to be present as methyl iodide, and 5 percent as particulate iodine.

Iodine removal mechanisms considered included plateout on containment surfaces and removal by a recirculating filter-adsorber system. Based on the work completed, it was concluded that the initial plateout rate would be governed by gas phase mass transfer resistance of elemental iodine. For the reference containment system design, airborne iodine would be removed by surface deposition at an exponential rate of $0.55 \mathrm{hr}^{-1}$. Due to equilibrium effects, the plateout rate would slow after the gas phase concentration decreased to about 1 percent of the initial value. Organics iodides, postulated to make up 10 percent of the iodine release, would not be removed at an appreciable rate by surface deposition. Operation of the filter-adsorber at a flow rate of $48,000 \mathrm{cfm}$ led to an exponential removal rate of $1.24 \mathrm{hr}^{-1}$. All iodine forms would be removed at about this rate because the filter-adsorber design permits efficient trapping of elemental, organic, and particulate iodines. According to the iodine depletion model used in the present study, surface-adsorbed iodine would be evolved to the gas phase after the gas phase concentration was reduced to less than about 1 percent of the initial (puff release) concentration. Iodine evolved from the surface slows the effective removal rate in the gas phase at long times.

Several alternative air cleaning processes were studied and their advantages and drawbacks briefly noted. 
PART I

PARTICULATE FISSION PRODUCT RELEASE AND REMOVAL ANALYSES FOR HTGR'S

by

J. A. Gieseke, E. W. Schmidt,

P. Baybutt, and H. Jordan

\section{ACCIDENT DEFINITION}

\section{Sequence of Events During DBDA and MHFPR}

For the purposes of this study two types of postulated accidents resulting in significantly different fission product release levels have been investigated. These are (1) the design basis depressurization accident (DBDA), and (2) the maximum hypothetical fission product release (MHFPR). The DBDA is the most severe mechanistic accident conceivable but the non-mechanistic MHFPR accident is more severe than the DBDA. For the evaluations performed in this study a reactor of the Fulton type (1) (1) (1160 MW(e)) has been assumed to be representative of a typical HTGR used for electrical power generation.

The DBDA is caused by a failure of one of the prestressed concrete reactor vessel (PCRV) penetration closures leading to the loss of the pressurized helium coolant. The maximum flow area through which the PCRV can depressurize is limited to 100 in $^{2}$ by design or flow restrictors in a reactor of the Fulton type. All penetration closures are independent of each other and therefore, the failure of one would not affect the others. An investigation has shown (1) that failure of the lower closure of the steam generator results in the highest containment pressure, the highest activity release from the PCRV, and hence the largest offsite doses.

The occurrence of a DBDA would initiate reactor trip within $\sim 10$ seconds on either low PCRV pressure or high containment pressure and control rods would be fully inserted and core power reduced to decay heat levels within $\sim 35$ seconds. Containment isolation occurs on a high activity signal. 
For a cold leg rupture, more than 90 percent of the total mass and energy content of the primary coolant is released to the containment during the first 3 minutes of the transient.

The MHFPR accident is postulated to occur as a result of

unrestricted core heatup ${ }^{(2)}$. It is not the result of any credible sequence of events and is considered only as a nonmechanistic source term postulated for the purpose of site evaluation. Therefore, a definition of the basis for the accident is necessary. This assumed accident has been described in the General Atomic Standard Safety Analysis Report (GASSAR) $^{(2)}$.

Release of fission produces from the fuel is time dependent and is driven by the slow heat-up of the core. The occurrence of the accident is assumed to initiate reactor trip after which the fuel temperature initially decreases as thermal equilibration with the 1ocal moderator occurs. The accident definition assumes that no core heat is removed by either forced or natural convection of primary coolant and thus fission product decay gradually heats the fuel and moderator. It takes about 20 minutes for the average fuel temperature to regain the average temperature of normal operation. As core temperatures increase further, fuel particle coatings begin to fail owing to temperature and pressure induced stresses and fission products may then be transported from the fuel through the primary system to the containment.

\section{Source Terms and Radionuclide Classification}

Source terms for the two accidents under discussion may be obtained by combining the fission product inventories and release fractions given in Tables $\mathrm{A}-1$ and $\mathrm{A}-2$ of Appendix $A$. The data in Tables A-1 and A-2 were taken directly from the Fulton Generating Station Preliminary Safety Analysis Report (FGS-PSAR) (1). Both 'design' and 'expected' inventories are given. The expected inventories are believed to be realistic, but still conservative, estimates while the design inventories were arbitrarily set higher than the expected inventories by a factor of about ten for most isotopes. The expected inventories have been employed in the work of this report. 
Particulate HTGR fission products may be classified in six chemical categories:
(a) alkalis (Cs, Rb)
(b) alkaline earths ( $\mathrm{Sr}, \mathrm{Ba})$
(c) noble metals (Y, $\mathrm{Zr}, \mathrm{Nb}, \mathrm{Mo}, \mathrm{Tc}, \mathrm{Ru}, \mathrm{Rh}, \mathrm{Pd}, \mathrm{Ag}$ )
(d) selenium group ( $\mathrm{Se}, \mathrm{Te}, \mathrm{Sb}, \mathrm{Sn}$ )
(e) lanthanides ( $\mathrm{La}, \mathrm{Ce}, \mathrm{Pr}, \mathrm{Nd}, \mathrm{Pm}, \mathrm{Sm}, \mathrm{Eu}$ )
(f) halogens ( $I, B r)$.

Several cases were investigated which considered different levels of mass release. The particle release levels were obtained by converting the radioactivities of Table A-1 to mass amounts, multiplying by the appropriate release fraction and converting the total mass concentrations to particle number concentrations based on an assumed particle size and distribution. Details of the cases investigated and the results are discussed later.

\section{Graphite Dust Data}

Metallic and halogen fission products will plate out on dust present in the primary system. This dust may be either suspended in the coolant or deposited on the primary system internals. It is important that the dust be characterized since its nature, composition, and size will affect fission product transport properties. Unfortunately, there is little information presently available; however, the FGS-PSAR indicates that (a) the concentration of particulate matter in the coolant is in the range 0.1 to $10 \mathrm{\mu g} / \mathrm{lb}$ helium, ( $b$ ) particle number is inversely proportional to particle size, and (c) the particulate matter consists of construction debris (pieces of metal, fibrous wool, weld spatter) and carbon (10-30 percent of total).

In order to demonstrate capabilities of the analytical model used in this study for handling variations in system dust concentrations and characteristics, several assumed levels for these variables were considered. The expected mass release levels were increased 100 times in 
some instances to account for the possible presence of large amounts of dust. Investigations were also conducted in which two different size ranges were considered in an attempt to model the effect of large dust particles.

\section{HTGR CONTA INMENT AND CLEANUP SYSTEM}

\section{HTGR Containment}

For the purposes of this study the containment design of the Fulton reactor was used as a model. The containment is a steel lined, sealed structure of reinforced concrete with a design internal pressure of 39 psig( 1 . This provides a margin above the peak DBDA pressure and temperature. The DBDA conditions give the maximum anticipated deleterious effects on the reactor containment.

Figure 1 is a schematic showing the physical arrangement of the containment and its related components. The $X^{\prime} s$ at the generator liner closures show the most likely locations for failures which lead to PCRV depressurization.

Table 1 gives the physical dimensions of the containment necessary to perform an aerosol behavior analysis.

TABLE 1. CONTAINMENT DIMENSIONS

\begin{tabular}{lr}
\hline Free Volume, $\mathrm{ft}^{3}$ & $2,526,000$ \\
Height, ft & 231 \\
Internal Diameter, ft & 140 \\
Floor Area, ft ${ }^{2}$ & 12,940 \\
Wall Area, ft & \\
Dome Area, $\mathrm{ft}^{2}$ & 47,900 \\
\hline
\end{tabular}




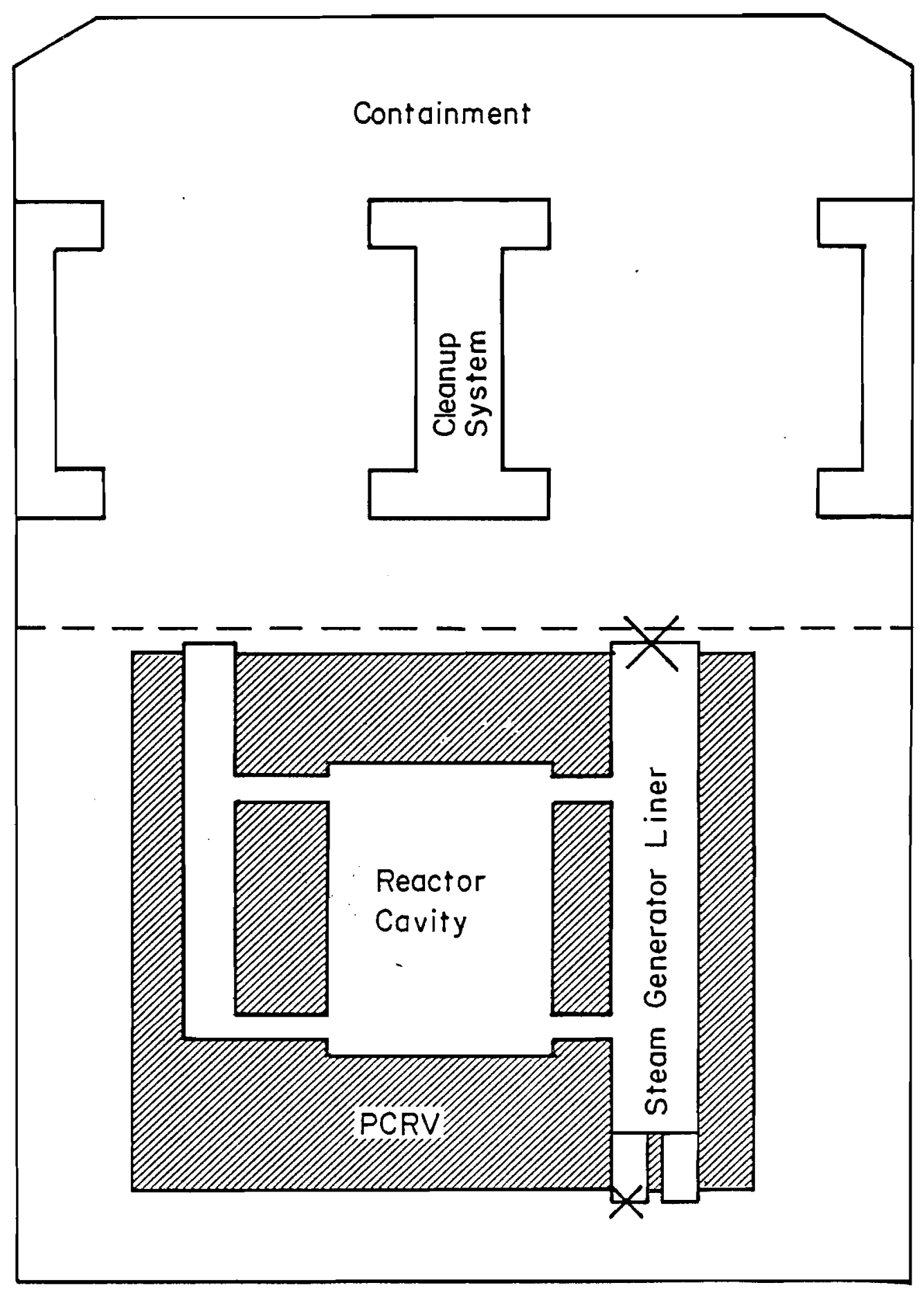

FIGURE 1. HTGR CONTA INMENT 


\section{Containment Conditions}

Under normal operating conditions the containment is at 1 to 2 psi above atmospheric pressure and at about $85^{\circ} \mathrm{F}$. Following a postulated depressurization accident the containment temperature and pressure are assumed to rise. Figure 2 shows the expected containment transients following a DBDA as calculated according to the FGS-PSAR ${ }^{(1)}$. For the analysis model, linear representations of these profiles shown in Figure 2 were used.

\section{Containment Cleanup System}

The containment cleanup system is composed of three 50 percent capacity loops each containing two charcoal filter trains in parallel and two circulation fans in parallel. A filter train consists of prefilters, high efficiency particulate air (HEPA) filter, unitary activated charcoal cells and HEPA filters in sequence. This system is designed with appropriate redundancy to remove both the particulate matter and iodine released following a postulated accident. The operation of two out of the three loops circulates and filters the containment air at a rate of one containment volume per hour. A complete description of the system may be found in Section 6.2.3.1 of the FGS-PSAR(1).

Although the system is designed such that the fans are temperature controlled to protect the filters and ensure proper operation, the model analyses conducted during this study conservatively assumed that the filtering mechanism would not be activated for 2 full hours following an accident.

\section{POSS IBLE AIR CLEANING CONCEPTS FOR USE IN AN HTGR}

Traditional dust collecting and air cleaning concepts have been adapted to nuclear facilities primarily for the purpose of removing radioactive particulate matter likely to be released should a postulated major accident occur. The current study has included a brief evaluation of some of the air cleaning concepts which appear suitable for use in a 

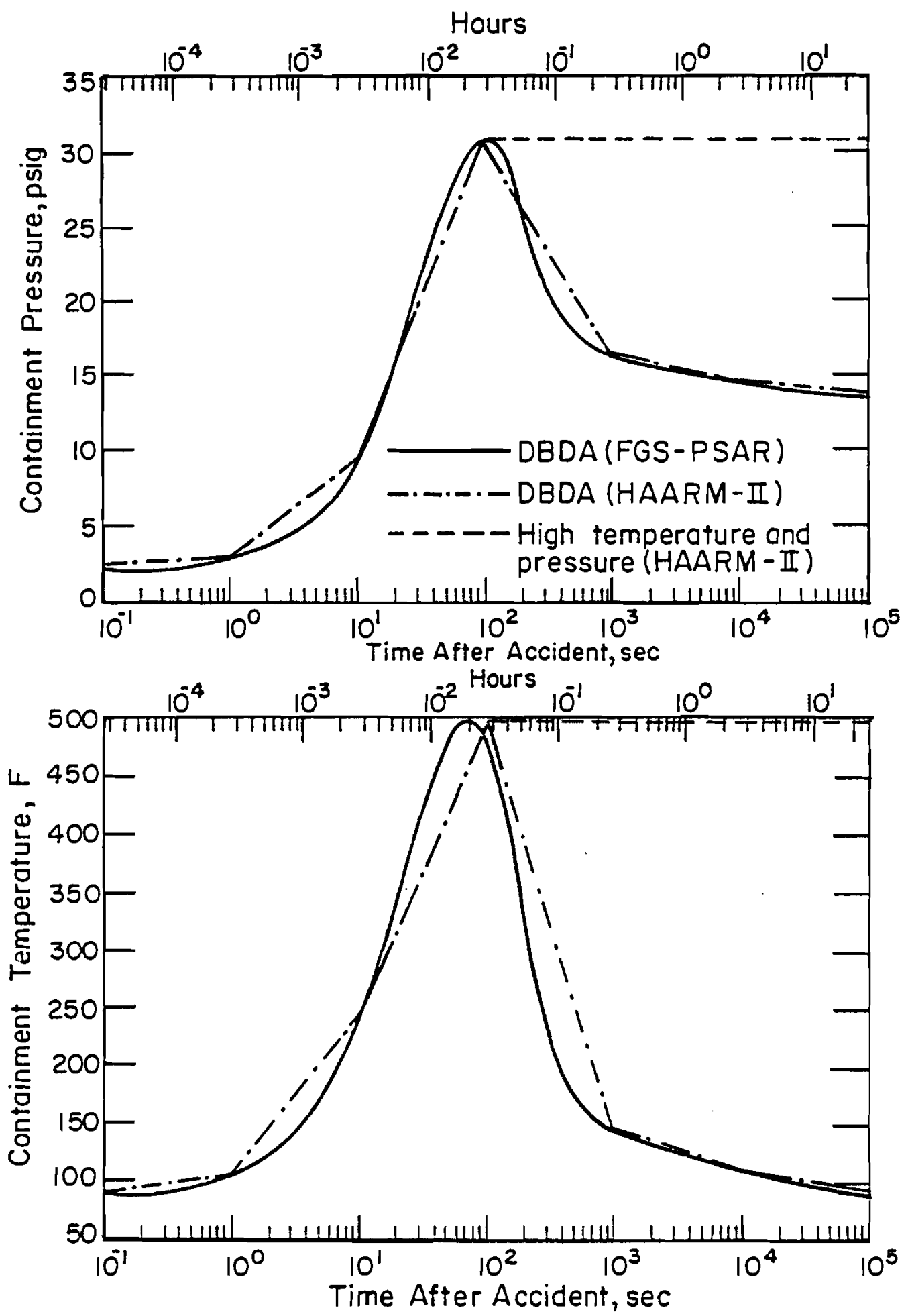

FIGURE 2. ESTLMATED AND ASSUMED HTGR CONTAINMENT CONDITIONS FOLIOWING POSTULATED DBDA 
HTGR. In this effort, some of the concept evaluations are based on adaptation to HTGR's of concepts evaluated for use in liquid metal cooled fast

breeder reactor (LMFBR) containments. (4)

These air cleaning concepts have been qualitatively evaluated

based on (1) anticipated performance, (2) degree of compatibility with HTGR's, and (3) cost. The performance evaluation of the various concepts was based on their effectiveness in removing particles and reliability including degradation under anticipated accident conditions. The degree of the concepts' technical development for the collection, removal, and disposition of contaminants as well as structural compatibility for installation in a HTGR were of primary concern. The relative costs of the different cleanup mechanisms include initial fabrication and installation, and maintenance.

For the purposes of this study the collection concepts have been divided into three categories according to the method by which particulates are removed. These categories are: (1) direct removal, (2) removal enhancement by alteration of the environment, and (3) combinations of methods in the previous two categories. The first category includes such techniques as filters, cyclones, and mechanical separators, whereas the second category includes air cleaning devices like powder dischargers and acoustic agglomerators. Table 2 summarizes the qualitative evaluation of several air cleaning concepts with respect to use in an HTGR. Excluded from the list of prospective air cleaning concepts is water spray removal owing to the possibility of the occurrence of the highly undesirable steam-graphite reaction which could result in the presence of hydrogen during a postulated HTGR accident.

\section{Direct Remova1 Mechanisms}

The first group of concepts evaluated included those mechanisms which directly remove particulate matter without any significant effect on the containment environment. The most desirable of these is a filter train consisting of high loading capacity prefilters followed by HEPA filters. This system is very effective and meets all 
TABLE 2. EVALUATION OF POSSIBLE AIR CLEANING CONCEPTS

\begin{tabular}{|c|c|c|c|c|c|c|}
\hline & \multirow[b]{3}{*}{ Method of collection } & \multirow{2}{*}{\multicolumn{2}{|c|}{ Performance }} & \multirow[b]{3}{*}{ Compat 1bility } & \multicolumn{2}{|c|}{ Est1mated Cost } \\
\hline & & & & & Inftal(4) & \\
\hline & & Removal Effectiveness & Rel1ab111ty & & m1111ons of $\$$ & Maintenance \\
\hline \multirow[t]{6}{*}{ I. } & D1rect Removal & & & & & \\
\hline & A. Prefilter, HEPA & $\begin{array}{l}\text { Excellent for entire } \\
\text { size range }(99.97 \%)\end{array}$ & Good & Good & 7.74 & Low \\
\hline & B. Cyclone & $\begin{array}{l}\text { Inefficlent for small } \\
\text { particles }\end{array}$ & Excellent & Good & 6.0 & $\begin{array}{l}\text { Large power } \\
\text { requil rements }\end{array}$ \\
\hline & C. Mechanical Separator & $\begin{array}{l}\text { Inefficient for smal1 } \\
\text { particles }\end{array}$ & $\begin{array}{l}\text { Poor, unsultable for } \\
\text { operation during } \\
\text { entire accident }\end{array}$ & Good & 6.6 & $\begin{array}{l}\text { Large power } \\
\text { requirements }\end{array}$ \\
\hline & $\begin{array}{l}\text { D. Recirculating Electro- } \\
\text { static Precipitator }\end{array}$ & Good $(85-99 \%)$ & Fa1r & Good & 7.8 & Moderate \\
\hline & E. Sand Bed Filter & Excellent $(99 \%)$ & Excellent & $\begin{array}{l}\text { Poor, large space } \\
\text { requirements }\end{array}$ & 13.8 & Low \\
\hline \multirow[t]{4}{*}{ II. } & Env1ronment Enhancement & & & & & \\
\hline & A. Powder Discharge & Excellent & Good & Fa1r & 3.92 & Moderate \\
\hline & B. Acoustic Agglomerator & $\begin{array}{l}\text { Particle growth } \\
\text { enhances removal }\end{array}$ & Good & Good & 2.83 & -- \\
\hline & $\begin{array}{l}\text { C. In-Containment Electro- } \\
\text { static Precipitator }\end{array}$ & Poor $(70 \%)$ & Fair & Poor & -- & $\cdots$ \\
\hline \multicolumn{7}{|c|}{ III. Comblnations } \\
\hline & A. Cyclone and HEPA & Excellent $(99.97 \%)$ & Excellent & Good & 6.8 & $\begin{array}{l}\text { Large power } \\
\text { requirements }\end{array}$ \\
\hline & $\begin{array}{l}\text { B. Acoustic Agglomerate } \\
\text { and Cyclone }\end{array}$ & Good & Good & Poor & 7.0 & $\begin{array}{l}\text { Large power } \\
\text { requirements }\end{array}$ \\
\hline
\end{tabular}


essential criteria. A recirculating electrostatic precipitator may serve as an adequate cleanup system; however, it is less effective, less reliable, and costs more than the filter train system. The inertial collectors cannot effectively collect small particles and have large power requirements. Other filtering mechanisms, such as sand bed filters require designs having large sizes and are not easily adaptable for use within reactcr containments.

\section{Removal Enhancement Mechanisms}

The second group of mechanisms are those which in some vay alter the containment environment to enhance particle collection. The three evaluated in this study are: (1) the addition of a collection medium (powder discharge), (2) Enancing agglomeratian with sound waves (acoustic agglomerator), and (3) increasing surface collection using elictrostatic charging (in-containment electrostatic precipitstor). Of these the third seems poor due to the relatively smal amount of increased collection one could expect for a significant increase in cost. The technical knowledge necessary to inject powder is not yet adequately developed. Iikevise precise knowledge of the effect of acoustic agglomeration on particle growth is insufficient for effective design or utilization.

\section{Combination Mechanisms}

Some shortcomings of individual mechanisms may be overcome by comoining two or more mechanisms for particulate cleanup. The use of a HEPA filter downstream of a cyclone alleviates the problem of a cyclone's poor collection efficiency for small particles. Acoustic agglomeration serves to increase particle size, thus erhancing the effectiveness of inertial collectors such as the cyclone, however, as mentioned previously, the ragnitude of the effect is difficult to evaluate. In general, the combination of filter types (prefilter and HePA filter) appears nost suited for HIGR application although a cyclone/HEPA could be similarly effective. 
ANALYSIS PROCEDURE

Applicability of Existing Aerosol

Behavior Codes to HTGR

Most investigations of aerosol depletion mechanisms have concentrated on containments of LMFBR's. This is because considerations of postulated LMFBR accidents predict much larger quantities of airborne particulates than for other types of reactors. Aerosol systems consisting of sodium oxide and fuel particles have been investigated both experimentally and analytically. Computer codes such as HAARM-2(5) have been developed to predict the behavior of aerosols within LMFBR containments.

To the extent that codes like HAARM-2 are applicable to the aerosol systems described above, they are also applicable to the DBDA and MHFPR accidents of an HTGR. The physical nature of the aerosols formed in these accidents is similar to that of the sodium oxide or fuel aerosol system in an LMFBR containment in that each is composed of two phases, an inert suspending gas and a solid particle phase. Applicability to HTGR systems results since particle removal mechanisms within the containment are essentially dependent on only the physical nature of the system. Questions of the chemical nature of the particle phase that might arise in terms of particle adsorption, reentrainment or particle-particle coalescence, are expected to be of negligible importance. The influence of radioactivity on aerosol behavior also appears to be insignificant (6) in affecting particle agglomeration or deposition rates.

If a third phase is added to the system, as is the case for steam blowdown of a light water reactor or in the event of steam leakage from a steam generator in an HTGR, additional particle removal mechanisms come into play that are not considered by the LMFBR aerosol codes. The current HAARM-2 code is therefore not applicable to these situations and modifications beyond those considered in this study would be required.

\section{Description of HAARM-2 Code}

Those mechanisms that play a role in the removal of particles during accidents will be summarized and a brief description of the manner in which they are analyzed by the HAARM-2 code will be given. More detail can be found in References 5,7 , and 8 . 
Under the assumption that the containment atmosphere is well mixed by natural convection currents or filter circulation systems, transport of particles is rate limited by transport through a stagnant boundary layer where diffusional or gravitational rather than hydrodynamic transport takes place. This assumption has been borne out for small and medium sized vessels under a broad range of conditions and is fundamental to the analytic description in HAARM-2 of the particle removal mechanisms. Particles entering this stagnant boundary layer are removed from further hydrodynamic transport and can be deposited on the walls of the containment by the following mechanisms:

(1) Brownian diffusion

(2) Thermophoresis

(3) Gravitational settling.

In addition to these "natural" removal mechanisms, HAARM-2 includes an aerosol leak rate and an aerosol source term. An aerosol removal term to account for filtration in a HTGR was added to extend the HAARM-2 code and make it applicable to the current study.

All of the above particle removal mechenisms are critically dependent on particle size which can be expected to be distributed over a wide range. This size distribution is continually modified by agglomeration between particles. Agglomeration mechanisms treated by HAARM-2, and the only significant ones for LMFBR as well as HTGR accident conditions, are assumed to result from Brownian motion of the particles and from differential settling velocities for particles of unequal mass, (gravitational agglomeration).

If $n(m, t) d m$ gives the number of particles of mass $m$ in $\mathrm{dm}$ at time $t$, then the rate of change of the distribution density due to agglomeration is given by $(5)$

$$
\begin{aligned}
\left.\frac{\partial}{\partial t} n(m, t)\right|_{a g g}= & \frac{1}{2} \int_{0}^{m} k\left(m^{\prime}, m^{\prime} m^{\prime}\right) n\left(m^{\prime}, t\right) n\left(m-m^{\prime}, t\right) d m^{\prime} \\
& -n(m, t) \int_{0}^{\infty} K\left(m, m^{\prime}\right) n\left(m^{\prime}, t\right) d m^{\prime} .
\end{aligned}
$$

For Brownian agglomeration, HAARM-2 exploys

$$
K_{B}\left(m, m^{\prime}\right)=\frac{4 k T}{3 \eta}\left(r+r^{\prime}\right)\left(\frac{r+a}{r^{2}}-\frac{r^{\prime}+a}{r^{\prime 2}}\right) \text {, }
$$


where

$$
\begin{aligned}
& r=\left(\frac{3 m}{4 \pi}\right)^{1 / 3} \text { is the particle (assumed spherical) radius } \\
& \rho=\text { particle density } \\
& a=\text { slip correction factor } \\
& \eta=\text { viscosity of carrier gas } \\
& k=\text { Boltzmann constant } \\
& T=\text { absolute temperature. }
\end{aligned}
$$

For gravitational agglomeration, HAARM-2 uses

$$
\begin{aligned}
K_{G}\left(m, m^{\prime}\right) & =\frac{2 \pi p g}{9 \eta} \varepsilon\left(m, m^{\prime}\right)\left|r \alpha(r)-r^{\prime} \alpha\left(r^{\prime}\right)\right| \\
\cdot & {\left[\left(r+r^{\prime}\right)^{3}+a\left(r+r^{\prime}\right)^{2}\right] }
\end{aligned}
$$

where the as yet undefined parameters are

$g=$ gravitational acceleration

$$
\begin{aligned}
\varepsilon\left(\mathrm{m}, \mathrm{m}^{\prime}\right) & =\text { particle-particle collision efficiency } \\
\alpha(\mathrm{r}) & =\text { particle shape and density factor. }
\end{aligned}
$$

The factor $\alpha(r)$ takes account of deviations of particle density from bulk material density due to loose packing during the agglomeration process. Its value is either estimated and read into the code or calculated within the code using an empirical relationship. The term $\varepsilon\left(m, m^{\prime}\right)$ corrects particle collision efficiencies to account for deviations from straight line flow of one particle past another due to curving stream lines. For spheres of radius $r$ and $r^{\prime}$ with $r \ll r^{\prime}$, one can show ${ }^{(9)}$ that

$$
\varepsilon \simeq \frac{3}{2}\left(\frac{r}{r^{1}}\right)^{2}
$$

This expression is employed in HAARM-2. The simultaneous action of Brownian and gravitational agglomeration is assumed to be additive so that the full kernel of Equation (1) can be written

$$
K\left(m, m^{\prime}\right)=K_{B}\left(m, m^{\prime}\right)+K_{G}\left(m, m^{\prime}\right) \text {. }
$$

The total rate of change of the size distribution density $n(r, t)=n(m, t) \frac{d m}{d r}$ is given by the superposition of the rate of change due to agglomeration, $\left.\frac{\partial n}{\partial t}(r, t)\right|_{\text {agg }}$ and the rate of change due to the deposition, source, and leak terms mentioned above. The rate of change of the size distribution density due to these is assumed equal to the sum of the rates of change due to each term separately. 
Writing the rate of change of the particle size distribution density due to diffusion as

$$
\left.\frac{\partial \mathfrak{n}}{\partial t}(r, t)\right|_{\text {diffusion }}=-\frac{k T A}{6 \pi \Pi_{r} \delta V}\left(1+\frac{a}{r}\right) n(r, t),
$$

where

$$
\begin{aligned}
& \mathrm{A}=\text { area of containment walls } \\
& \mathrm{V}=\text { volume of containment } \\
& \delta=\text { containment wall boundary layer thickness; }
\end{aligned}
$$

the rate of change of the particle size distribution density due to gravitational settling as

$$
\left.\frac{\partial n}{\partial t}(r, t)\right|_{\text {settling }}=-\frac{2 r^{2}}{9 \eta} g \rho\left(1+\frac{a}{r}\right) \frac{A}{V} n(r, t) ;
$$

and that due to thermophoresis as

$$
\begin{aligned}
\left.\frac{\partial n}{\partial t}(r, t)\right|_{\text {thermo }} & =-\frac{3}{2} \frac{n}{\rho_{g} T}\left(\frac{1}{I+2 C_{m} I / r}\right) \\
& \cdot\left(\frac{C_{t} \frac{I}{r}+\frac{k_{f}}{k_{S}}}{I+2 C_{t} \frac{I}{r}+2 \frac{k_{E}}{k_{s}}}\right) \frac{\nabla T A_{T}}{V} n(r, t),
\end{aligned}
$$

where

$$
\begin{aligned}
& \rho_{g}=\text { density of suspending gas } \\
& I_{=} \text {mean free path of suspending gas } \\
& k_{f}=\text { themal conductivity of the suspending gas } \\
& k_{S}=\text { thermal conductivity of the particle } \\
& C_{E}=\text { constant related to the momentum accomnodation at the } \\
& C_{t}=\text { constant related to the thermal accomodation at the } \\
& \quad \text { particle surface } \\
& \nabla T=\text { temperature gradient at the containment vall } \\
& A_{T}=\text { area of containment wall experiencing temperature gradient; }
\end{aligned}
$$


then the total rate of change of the size distribution density as programed in HAARM-2 (modified for filter removal) is

$$
\begin{aligned}
\frac{\partial n}{\partial t}(r, t)= & \left.\frac{\partial n}{\partial t}(r, t)\right|_{\text {agg }}+\left.\frac{\partial n}{\partial t}(r, t)\right|_{\text {diffusion }}+\left.\frac{\partial n}{\partial t}(r, t)\right|_{\text {sett1ing }} \\
& +\left.\frac{\partial n}{\partial t}(r, t)\right|_{\text {thermo }}-L(t) n(r, t)-F n(r, t)+S(r, t) .
\end{aligned}
$$

Here

$$
\begin{aligned}
\mathrm{L}(\mathrm{t}) & =\text { fractional leak rate as a function of time } \\
\mathrm{F} & =\text { fractional filter removal rate } \\
\mathrm{S}(\mathrm{r}, \mathrm{t}) & =\text { source rate as a function of particle radius and time. }
\end{aligned}
$$

Given the size distribution density as a function of time, the various quantities of interest, such as

- suspended number concentration

- suspended mass concentration

- cumulative mass deposited on walls and floor due to the various deposition mechanisms

- mass leaked as a function of time

- cumulative mass deposited in filter, can readily be found by integration. This is done by HAARM- 2 and the results presented in tabular form. The time dependencies of

- the leak rate

- the source rate

- temperature

- temperature gradient at wall

- pressure

are read into the program. The degree to which variations in temperature and pressure affect aerosol behavior is discussed later.

The numerical solution of Equation ( 7 ) is a current topic of research ${ }^{(10)}$. Detailed numerical treatments ${ }^{(11)}$ require inordinate amounts of computer time for all but the simplest cases. It is therefore essential to make simplifying approximations on the development of the particle size distribution density with time, permitting partial 
analytical solution. The approximation made in HAARY-2 is that the particle size distribution is lognormal for all time. This assumption is borne out quite well by experiment and comparison with more detailed codes (12) for typical situations. Whether or not the lognormal assumption produces accurate results for all situations is open to debate.

In particular, in order to accomodate situations in which an instantaneous source of particles is supplemented by a long term source of different average particle size, the existing airborne particle size distribution and the source particle size distribution are combined in HAARY-2 in such a way that a lognormal size distribution results whose first three moments are equal to the first three moments of the added distributions.

\section{HAARM-2 Modification to Include Filtration}

In order to be able to assess the effect of engineered particle removal mechanisms on the HTGR containment, the HAARM-2 code was modified for this study to include a filter removal term. It is included in Equation (7) as

Filter removal rate $=F n(r, t)$.

Parameters included in the modified HAARM-2 code specifying the filter removal term are

- time filter operation starts

- time filter operation stops

- fraction of containment volume drawn through filter per unit time

- filter efficiency. 
DESCRIPTION OF THE PARTICULATE REMOVAL MECHANISMS

AND THEIR DEPENDENCE ON PARTICLE SIZE, CONTA INMENT CONDITIONS AND CONTA INMENT GEOMETRY

The rate of particulate removal from the containment environment following a postulated accident and thus, the subsequent amount of radioactive contamination are dependent on several parameters. The most significant of these parameters are the particle size, the containment conditions (temperature and pressure), and the containment geometry. The modified HAARM- 2 code used in the current study accounts for any of four possible mechanisms: (1) removal at the vessel floor due to gravitational settling, (2) diffusion to the walls (wall plating), (3) leakage out of the vessel, and (4) removal by a filter system. Mathematically formulated, the removal terms $R(x)$ may be expressed as

$$
R(x)=G_{R} r(r+a)+P_{R} \frac{1}{r^{2}}(r+a)+R_{L}+R_{F} E_{F} \text {. }
$$

\section{Gravitationa1 Settling}

The gravitational settling removal term, $R_{G}$, is expressed as

$$
R_{G}=G_{R} r(r+a) \text {, }
$$

where

$$
\begin{aligned}
G_{R}= & \text { settling constant } \propto \frac{1}{h \eta} \\
a= & \text { Cunningham correction term } \propto \frac{\mathrm{p}}{\mathrm{T}} \\
& (\text { significant only for small particles). }
\end{aligned}
$$

Further, $r$ is the particle radius, $h$ the containment height, $\Pi$ the gas viscosity, $\mathrm{p}$ the containment pressure, and $\mathrm{T}$ the containment temperature. It has been shown ${ }^{(13)}$ that

$$
\eta \propto T^{1 / 2} \text {. }
$$

Thus, in general, the gravitational removal is directly proportional to the square of the particle size and inversely proportional to the vesse 1 height and the square root of temperature. Simply 
stated, the gravitational removal term attains greater importance in relation to the other removal mechanism as the particle size increases, the temperature decreases, and the containment height lessens.

\section{Wall Plating}

Removal by particle diffusion to the walls is expressed as

$$
R_{P}=P_{R} \frac{1}{r^{2}}(r+a),
$$

where

$$
P_{R}=\text { plating coefficient } \propto \frac{T A_{w}}{T V}
$$

$A_{W}$ is the wall area and $V$ the vessel volume.

Wall plating is therefore inversely proportional to particle size and directly proportional to the ratio of the wall area to volume. Due to the Cunningham correction term $\left(a \propto \frac{P}{T}\right)$ no exact statement may be made concerning the plating removal dependence on temperature. In general, however, plating can be considered directly proportional to the square root of temperature. The importance of wall plating as a particulate removal mechanism following an accident increases with decreasing particle size, increasing temperature, and increasing wall area per containment volume.

\section{Leakage}

The removal of particulates due to leakage is based on a fixed rate (or a series of rates as a function of time) and thus, is not directly affected by the various parameters.

\section{Filter Removal}

The filter removal term is given by a flow rate through the filter $\left(R_{F}\right)$ times a removal collection efficiency ( $\left.E\right)$. In a real sense the filter collection efficiency will be a function of size. The resulting 
curve of efficiency versus size would be a characteristic V-shape curve due to diffusional collection of small particles and inertial collection of large particles with a minimum collection point typically a diameter of about $0.3 \mu \mathrm{m}$. However, for the purposes of this study the filter mechanism is conservatively assumed to collect all particles at the minimum efficiency. Thus, filter removal of particulates is not directly affected by the various parameters.

\section{FISSION PRODUCT RELEASE SOURCE TERMS}

Radioactivity released to the containment from the primary system during a depressurization accident can come from four sources within the PCRV:

(1) The activity present in the primary helium coolant. During normal operation of a HTGR a percentage of the more volatile fission products diffuse from the reactor core fuel particles into the primary coolant. This fission product release, coupled with the removal of fission products by decay, plateout, and the operation of the helium purification system, determines the activity level in the primary coolant. The coolant fission product inventory is carried out of the PCRV during depressurization along with the helium coolant.

(2) The activity plated out or sorbed on the structures within the PCRV.

Metallic fission products and halogens which are released to the primary coolent during normal operation of an HTGR tend to plate out on the colder parts of the coolant circuit, mainly the steam generators, or sorb on metal surfaces. These may be lifted off, or desorbed, and blown into the containment during depressurization owing to increased shear forces. 
(3) The activity which is sorbed on core structural materials (fuel rod filler material and graphite moderator). Fission products which escape from core fuel particles during normal operation of an HTGR pass into the primary coolant by diffusion through the fuel rod filler material and graphite moderator. During this transport process some of the fission products sorb on the transportation medium. A percentage of this sorption inventory may be desorbed during a depressurization or core heat-up by diffusion to and evaporation from the filler and graphite surfaces.

(4) Fuel particle activity.

Fuel particle coatings may fail during an accident owing to increased material stresses and thus lead to fission product release.

It has been concluded that the only significant fission product source terms for a DBDA would be the coolant and plateout activities. The MHFPR accident adds to these activities, fission product losses from the fuel particles. As the derivation of these source terms is outside the scope of this work, the calculations of aerosol behavior for HTGR source terms were performed in several initial aerosol concentrations. The cases analyzed envelope the DBDA source term as we11 as the 1 percent solid release assumption of the MHFPR. 


\section{REMOVAL OF PARTICULATES FROM THE CONTAINMENT}

Using the modified HAARM-2 computer code, the aerosol behavior within a HTGR containment following postulated accidents with varying parameters was investigated. This study shows the broad adaptability of the code to analyze the aerosol behavior using a wide range of accident parameters. Table 3 shows the various parameters for each of the ten cases investigated.

\section{Effect of Concentration Leve1}

The variable most determinant of the suspended concentration and thus the subsequent leaked mass is the initial amount of particulate material released. In order to demonstrate the ability of the model to handle a wide range of releases, five different levels of release were investigated. In addition, a sixth release, modeling the MHFPR release as described in GASSAR, was investigated. The results show the model's feasibility over five orders of magnitude of release concentration.

The various release levels were combinations of the expected coolant inventory, the expected plateout inventory, and the fuel inventory of radionuclides as given by Table A-1. Two levels of particulate coolant and plateout release concentrations were obtained by assuming the iodine present to be either (1) entirely in a solid state, or (2) entirely in a gaseous state. In addition, certain cases assumed the release concentration of particulates increased 100-fold to account for the possible presence of graphite and other debris. Table 4 gives the basis for the release levels of the various cases. 


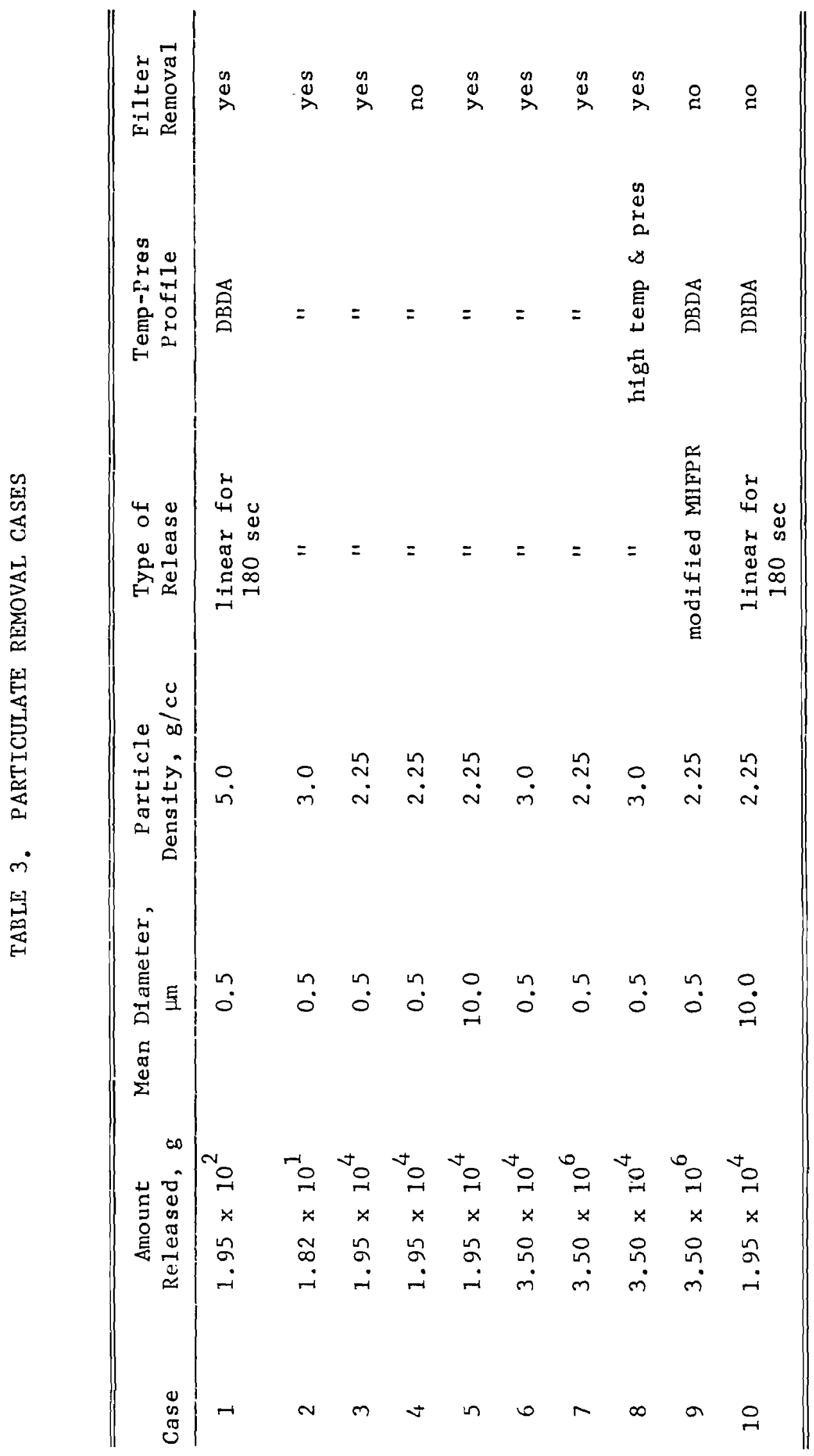


Five cases being considered were analyzed with a linear fission product release over a 180 second period. This corresponds to the DBDA blowdown. A sixth case (No. 9) was run in which the coolant and plateout inventories were considered to be released linearly over 180 seconds followed 4 hours later by a linear 16 hour fuel element fission product release. This type of release would correspond to the MHFPR as presented in the FGS-PSAR ${ }^{(1)}$ (Appendix C, Figure C.1-1).

Results calculated with the modified HAARM-2 code for those cases illustrating the effects of released mass are shown in Figures 3 and 4. Figure 3 shows the predicted suspended mass concentrations versus time for these various cases and Figure 4 shows the corresponding leaked mass based on a leak rate of 0.1 percent per day for 1 day followed by 0.05 percent per day thereafter. These cases all assume proper operation of the containment filter cleanup system beginning 2 hours after the accident, except for Case No. 9 which assumes no filter removal of particulates.

\section{Effect of Filter Removal}

The filter cleanup system operating nominally $\left(R_{F}=\right.$ one containment volume per hour) provides a significant particulate removal mechanism. To show this effect two cases, Nos. 3 and 4, were analyzed. These analyses are based on the same assumptions (identical release and containment conditions) except that Case No. 4 has no filter removal mechanism whereas Case No. 3 accounts for nominal filter cleanup operation beginning 2 hours after the accident. A filter collection efficiency of 0.997 (the likely minimum HEPA filter efficiency) is assumed. A comparison of the respective suspended concentration curves of Figure 5 shows the dominant filter removal effect. Comparisons of the amount of mass leaked from each case are shown in Figure 4. 
TABLE 4. RELEASE BASIS

\begin{tabular}{|c|c|}
\hline Case & Release Basis(a) \\
\hline 1 & $\begin{array}{l}\text { Expected coolant and plateout inventory release } \\
\text { including iodine }\end{array}$ \\
\hline 2 & $\begin{array}{l}\text { Expected coolant and plateout inventory release no: } \\
\text { including iodine }\end{array}$ \\
\hline 3 & $\begin{array}{l}\text { Expected coolant and plateout inventory release } \\
\text { times } 100 \text {, to account for the graphite and debris } \\
\text { possibly present }\end{array}$ \\
\hline 4 & $\begin{array}{l}\text { Expected coolant and plateout inventory release times } \\
100 \text {, to account for the graphite and debris possi- } \\
\text { bly present }\end{array}$ \\
\hline 5 & $\begin{array}{l}\text { Expected coolant and plateout inventory release times } \\
100 \text {, to account for the graphite and debris possi- } \\
\text { bly present, initial particle size assumed different }\end{array}$ \\
\hline 6 & $\begin{array}{l}\text { Expected coolant and plateout inventory release and } \\
1.0 \text { percent of the fuel inventory }\end{array}$ \\
\hline 7 & $\begin{array}{l}\text { Expected coolant and plateout inventory release and } \\
1.0 \text { percent of the fuel inventory times } 100 \text {, to } \\
\text { account for the graphite and debris possibly present }\end{array}$ \\
\hline 8 & $\begin{array}{l}\text { Expected coolant and plateout inventory release and } \\
1.0 \text { percent of the fuel inventory }\end{array}$ \\
\hline 9 & $\begin{array}{l}\text { Expected coolant and plateout inventory release and } \\
1.0 \text { percent of the fuel inventory times } 100 \text {, to } \\
\text { account for the graphite and debris possibly present }\end{array}$ \\
\hline 10 & $\begin{array}{l}\text { Expected coolant and plateout inventory release times } \\
100 \text {, to account for the graphite and debris possi- } \\
\text { bly present, initial particle size assumed different }\end{array}$ \\
\hline
\end{tabular}

(a) Table A-2 gives fractional release of plateout inventory according to type of fission product. 


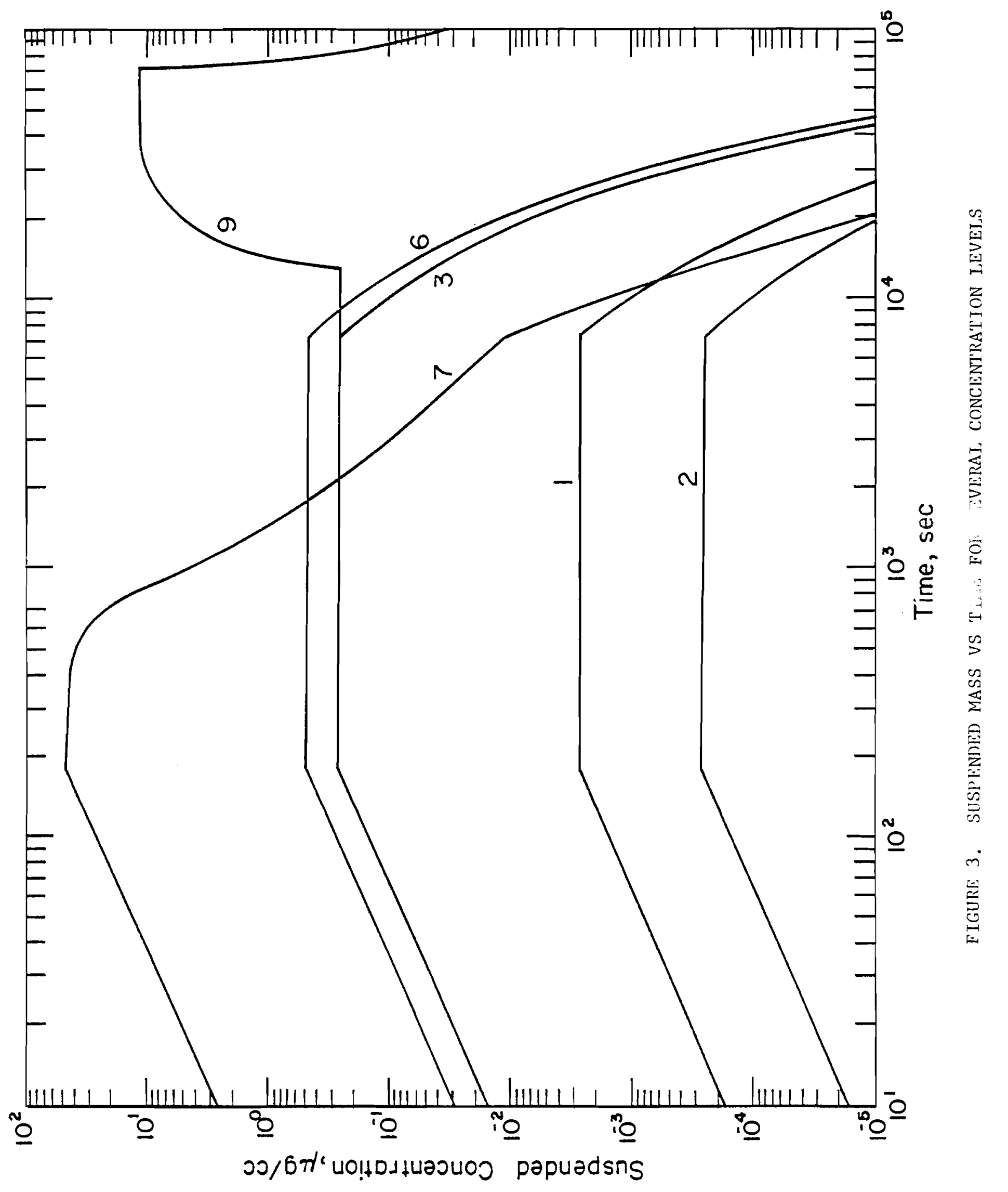




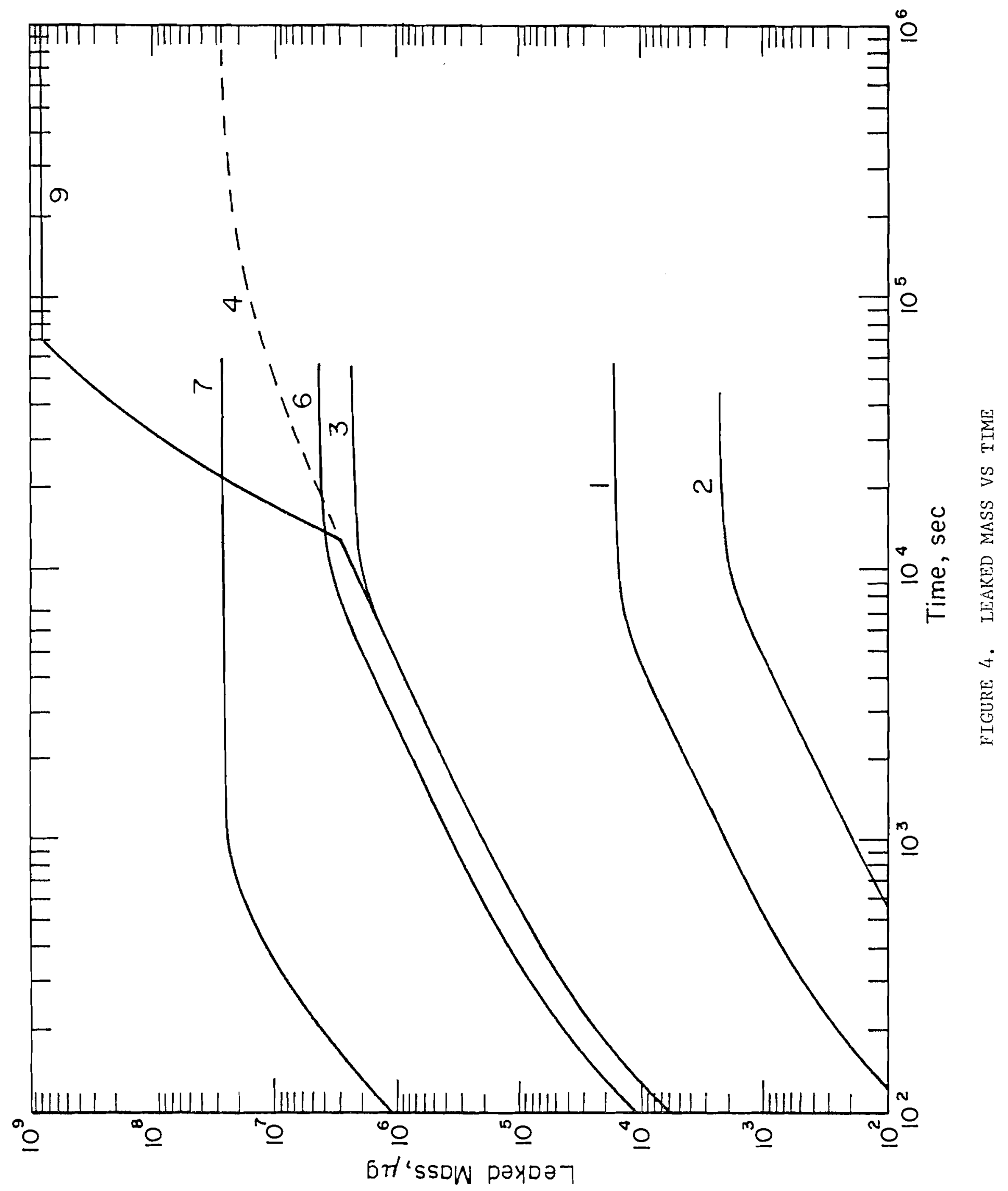




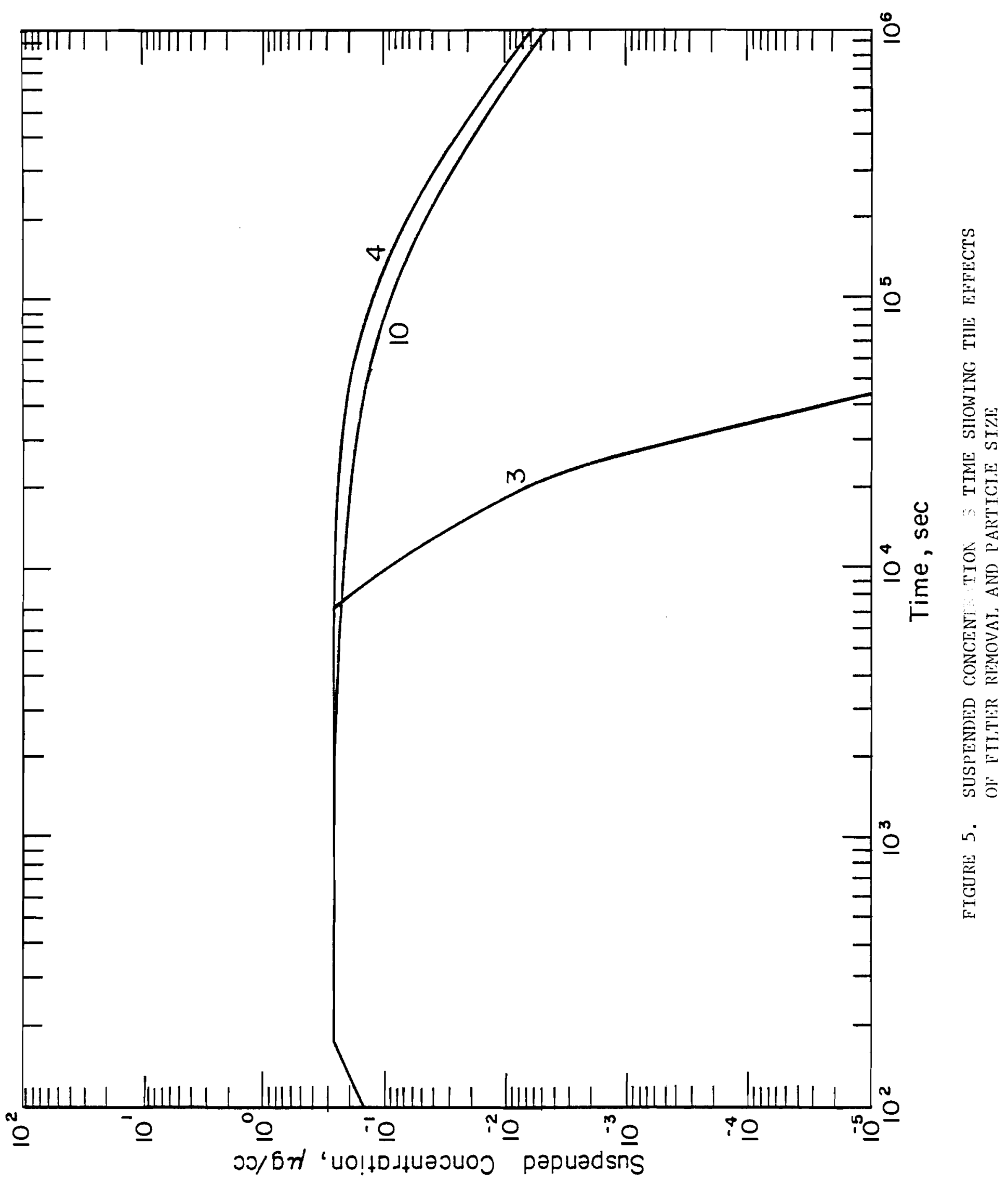




\section{Effect of Size}

A change in the initial size of suspended material had little effect on predicted particulate mass removal. Figure 5 shows the time dependent suspended concentration for Case Nos. 4 and 10 in which the initial particle diameter was assumed to be $0.5 \mu \mathrm{m}$ and $10.0 \mu \mathrm{m}$, respectively. Despite this significant initial size difference the rates of particulate mass removal are surprisingly similar. This may be attributed to the increased number concentration of the smaller particles of Case No. 4 resulting in greater agglomeration rates and thus rapid particle growth.

\section{Effect of Temperature and Pressure Profile}

The aerosol behavior in the containment was examined under two different temperature and pressure profiles as stated earlier (Figure 2). Comparing Case Nos. 6 and 8, essentially no difference was seen in the resulting analyses (accountable to the differences in the temperature and pressure profiles not being great); however, the capability of using different varying temperature and pressure profiles with the HAARM-2 code was demonstrated.

\section{Conclusions}

The modified HAARM-2 used in this study has been shown to be adaptable to a wide range of parameters. The capability of handing calculations for various levels of particulate mass concentration, particle characteristics, and containment conditions has been demonstrated. The ability to analyze the effect of a particular removal mechanism, such as the filter cleanup system, has also been shown. However, this model represents the current state-of-the-art. Further code verifications are needed to demonstrate suitable accuracy and conservatism. 
The results obtained with the modified HAARM 2 Code demonstrated the need for accurate definition of the particulate source term. The assumption for the MHFTR source term of 1 percent results in suspended mass concentrations which warrant consideration in accident dose calculations.

An attempt at the evaluation of more realistic source terms must include improvement of the experimental data base upon which the fission product transport and deposition models are founded and also refinement of the models themselves. The HAARM 2 calculations also demonstrate the effectiveness of high efficient filter systems such as the one analyzed.

\section{Need for Further Code Development}

The two-phase physical enviroment of the HTGR accident situations discussed in this report permits treatment of the associated aerosol behavior with the HAARM-2 Code as described. It is, however, conceivable that the three-phase accident environments could arise for accidents not considered in this report. In particular, it is conceivable, if highly improbable, that malfunction of a steam generator could lead to steam injection into the prestressed concrete reactor vessel (PCRV) with concomitant graphite-steam reactions. The steam and reaction heat would constitute a driving force for water vapor and fission product transport from the PCRV to the containment.

At present, no code exists that describes aerosol behavior in a water vapor saturated environment. In such an environment aerosol behavior is strongly influenced by the degree of water vapor condensation on the airborne particles. This in turn depends critically on the degree of saturation. It is clear that while the underlying assumption of existing aerosol codes, that the system be homogeneously mixed with respect to particle concentration, might well be approximately fulfilled for full scale containments, the analogous and necessary assumption that the degree 
of saturation be independent of spatial coordinates, cannot be fulfilled to the degree of precision required. Particle growth rate due to condensation is sensitively dependent on the degree of saturation.

In lieu of the existence of a code to treat three-phase aerosol systems, HAARM-2 may be used with some assurance of conservatism by ignoring water vapor effects since these can be expected to accelerate particle deposition. However, further code verification is needed to demonstrate suitable accuracy and conservatism. 


\section{REFERENCES}

(1) "Fulton Generating Station - Preliminary Safety Analysis Report", Philadelphia Electric Co., Pennsylvania, 1973.

(2) "General Atomic Standard Safety Analysis Report", GA-A13200, General Atomic, San Diego, California, 1975.

((3) "HTGR Accident Initiation and Progression Analysis Status Report", GA-A13617, General Atomic, January, 1976.

(4) Hilliard, R. K, et a1., Evaluation of Air Cleaning System Concepts for Use in LMFBR PIants, TC-536, Hanford Engineering Division Laboratory, Richland, Washington, Dec. 22, 1975.

(5) I. D. Reed, J. A. Gieseke, "HAARM-2 User's Manua1", BMI-X-665, October $31,1975$.

(6) I. D. Reed, J. A. Gieseke, H. Jordan, "Effects of Radiation on Aerosol Behavior", BMI-NUREG-1963, December 18, 1975.

(7) I. D. Reed, J. A. Gieseke, "HAARM-1 User's Manua1", BMI-X-658, May $15,1975$.

(8) J. A. Gieseke, R. C. Behn, A. S. Chace, L. D. Reed, "Analytic Studies of Aerosol Behavior Predictions for Fast Reactor Safety", BMI-1932, March 18, 1975.

(9) N. A. Fuchs, The Mechanics of Aerosols, The MacMillan Company, New York, 1964.

(10) J. A. Gieseke, I. D. Reed, "Aerosol Behavior Modeling for Fast Reactor Safety, FY1975 Annual Safety Report", BMI-X-662, October, 1975.

(11) H. Jordan, W. Schikanski, H. Wild, "Nukleare Aerosole im geschlossen System", KFK1989, October, 1974.

(12) H. Jordan, "A Comparison of HAARM-2 and PARDISEKO-III", BMI-X-667, December 29, 1975.

(13) Hilsenrath, J., et al., Tables of Thermal Properties of Gases, NBS Circular 564, Washington, 1955. 
APPENDIX A

TABLES USED TO OBTAIN PARTICULATE RELEASE ESTTMATES 


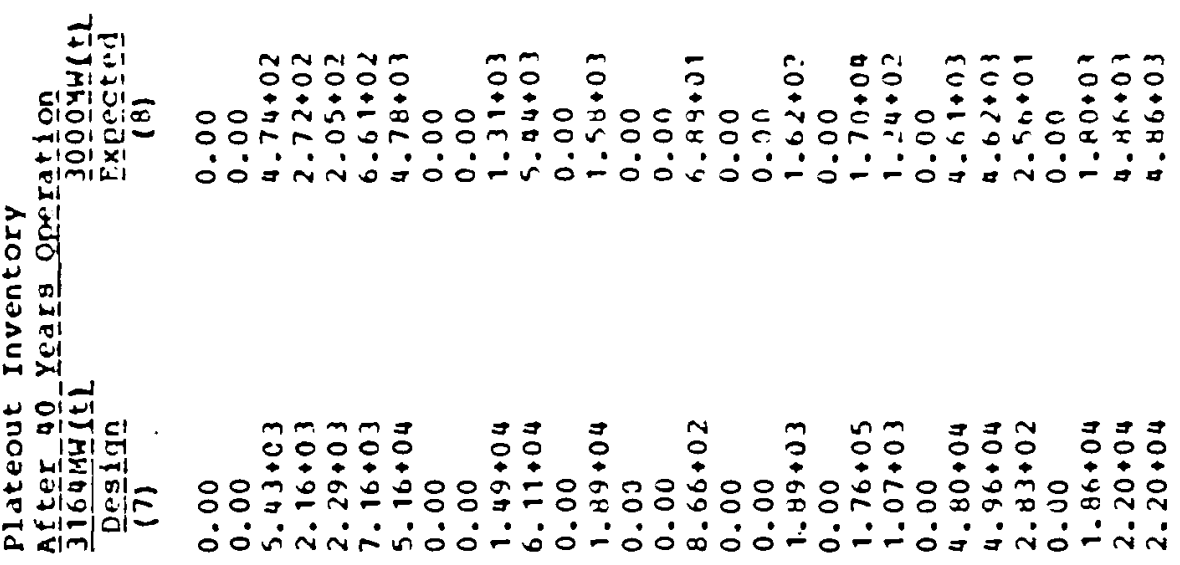
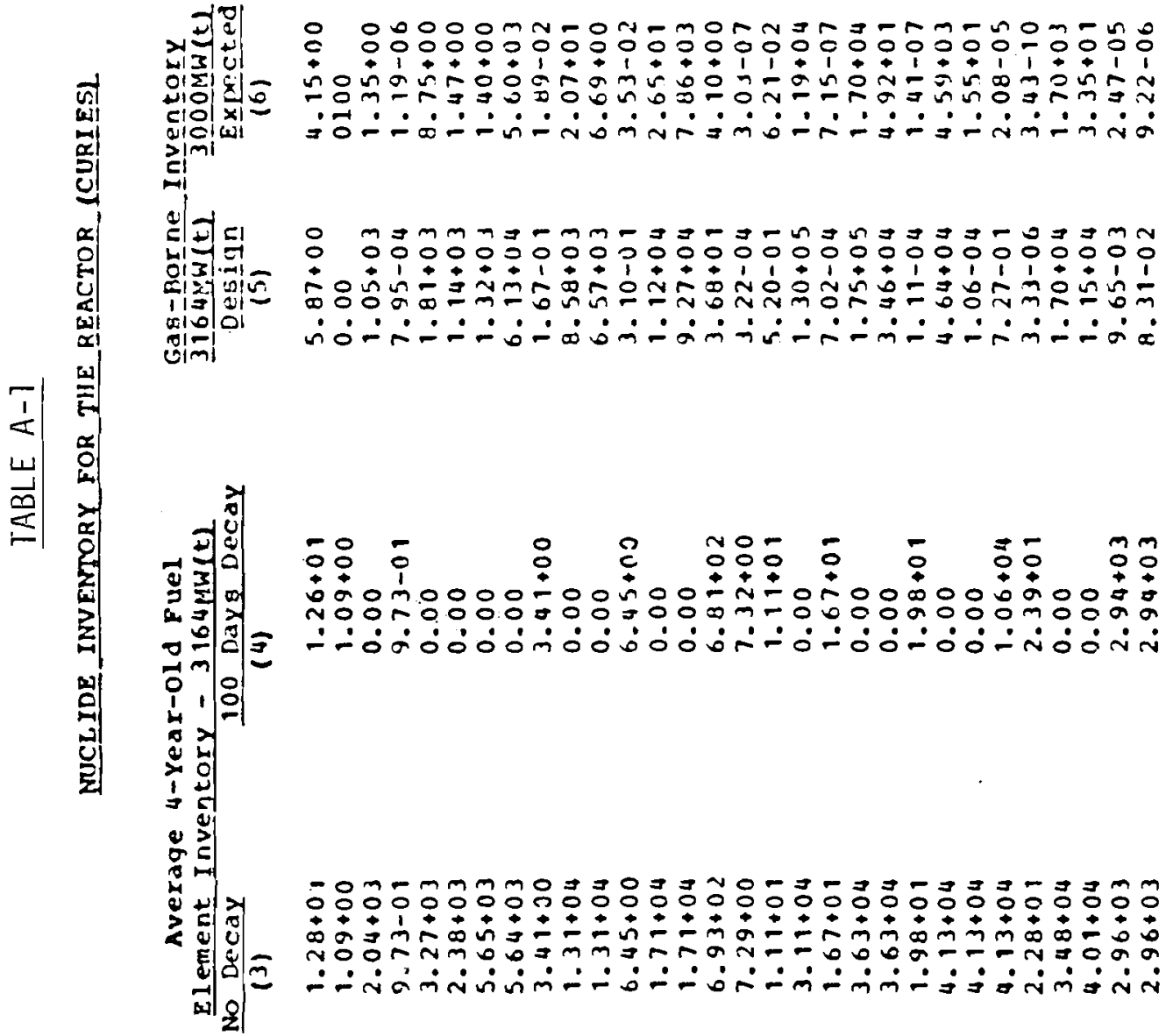

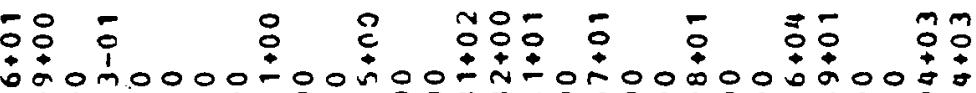

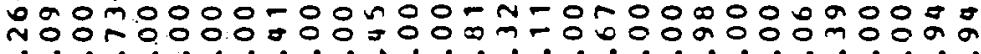

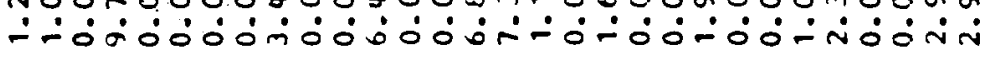

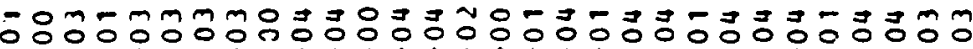

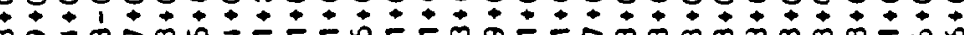

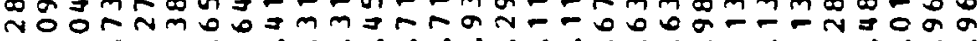

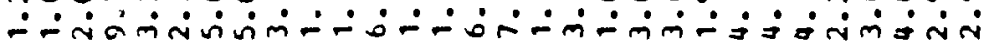

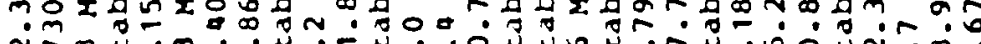

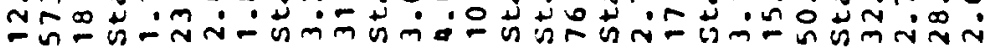

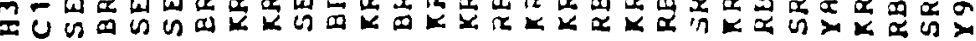



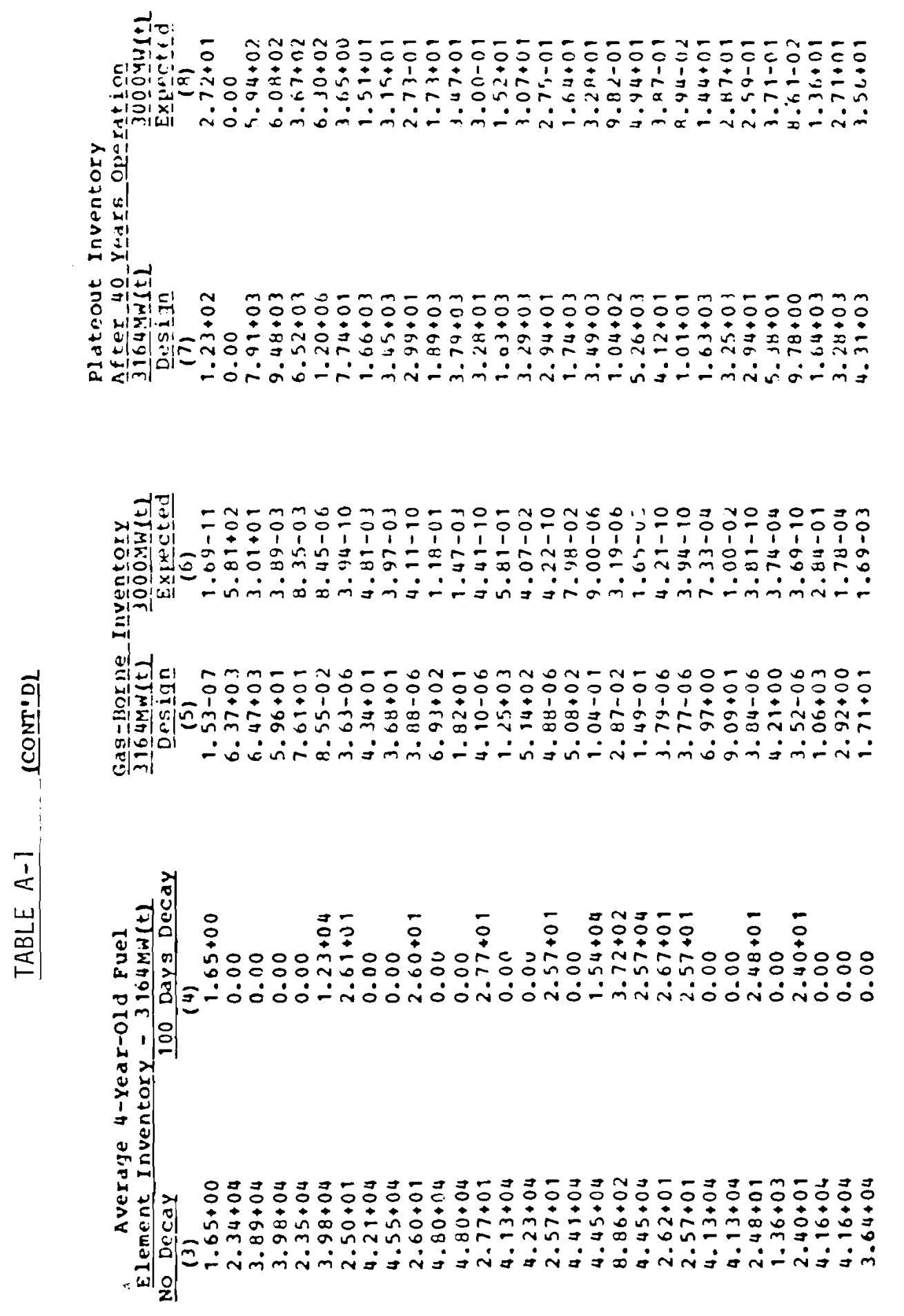

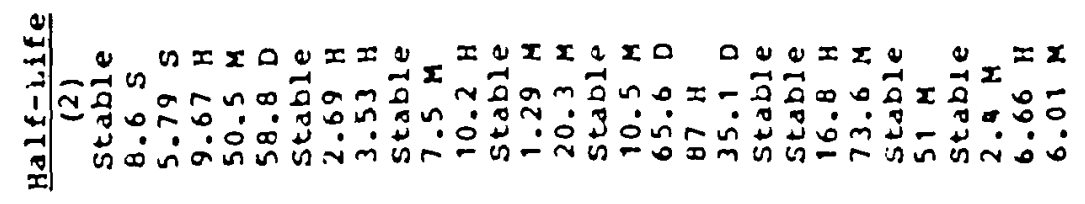

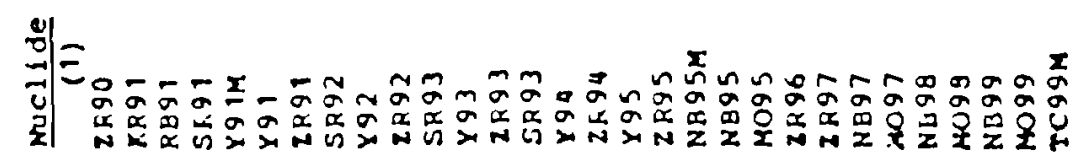



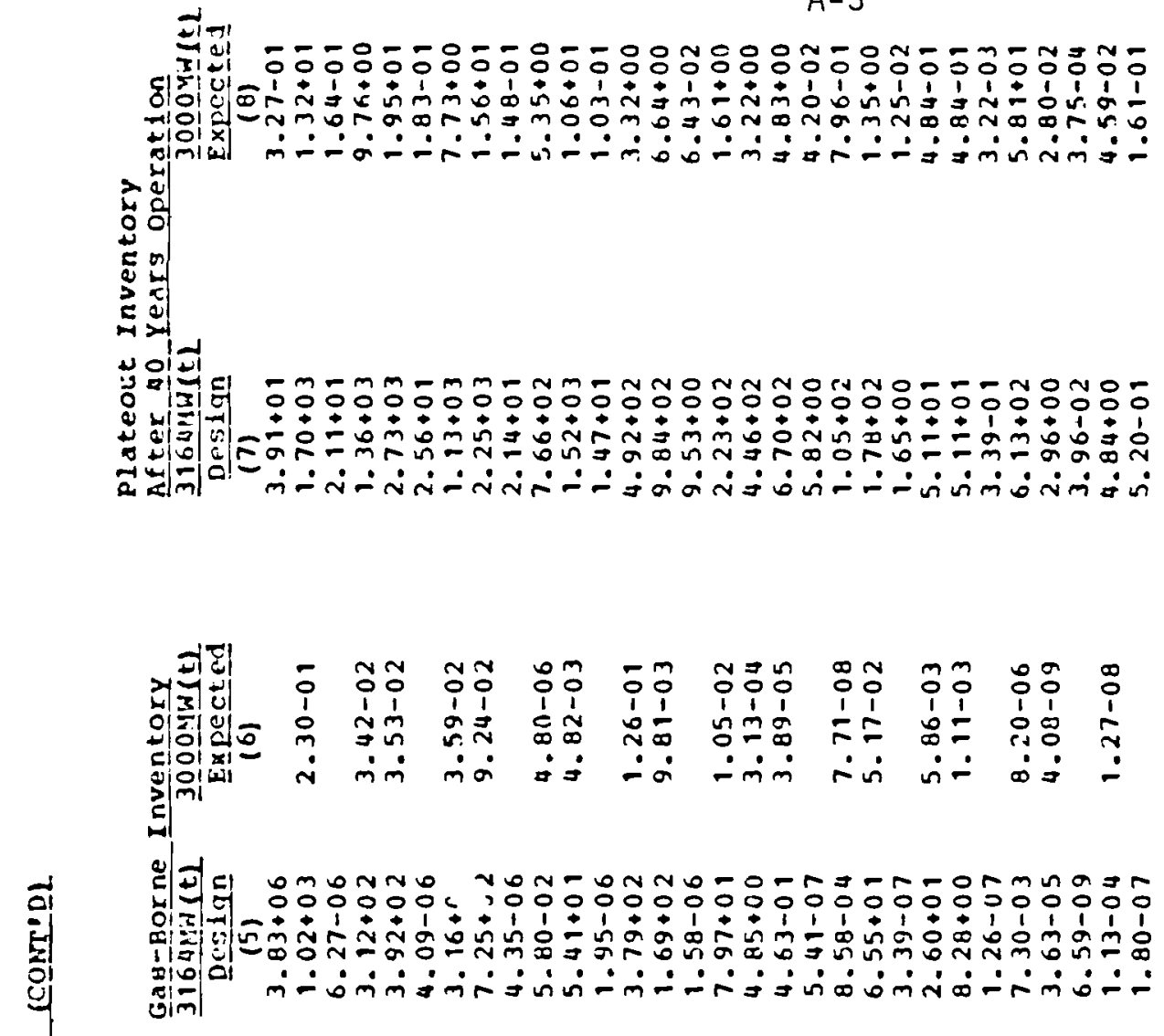

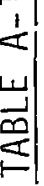

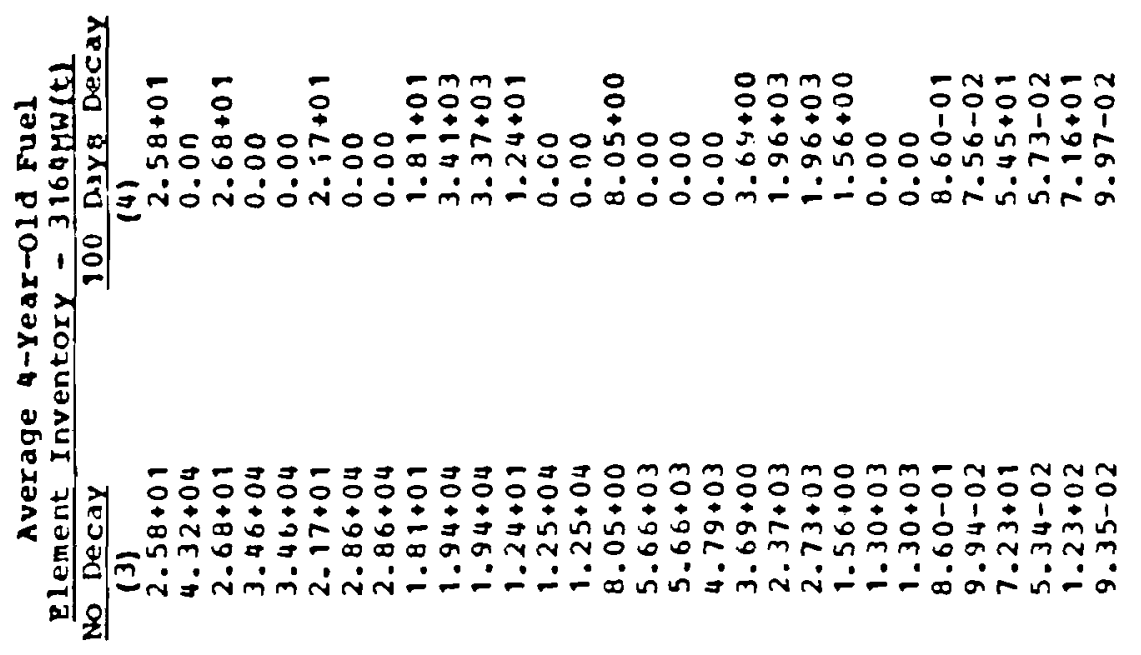

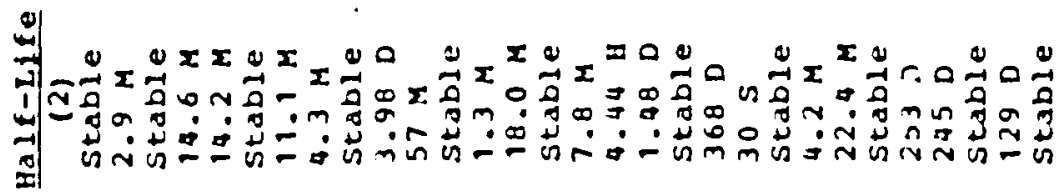

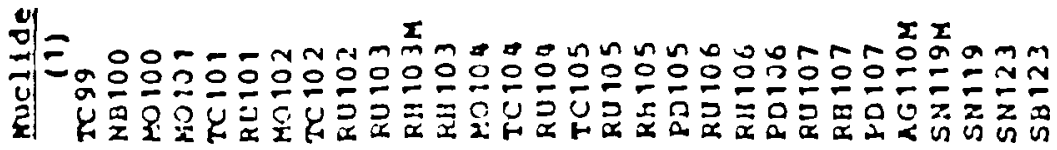



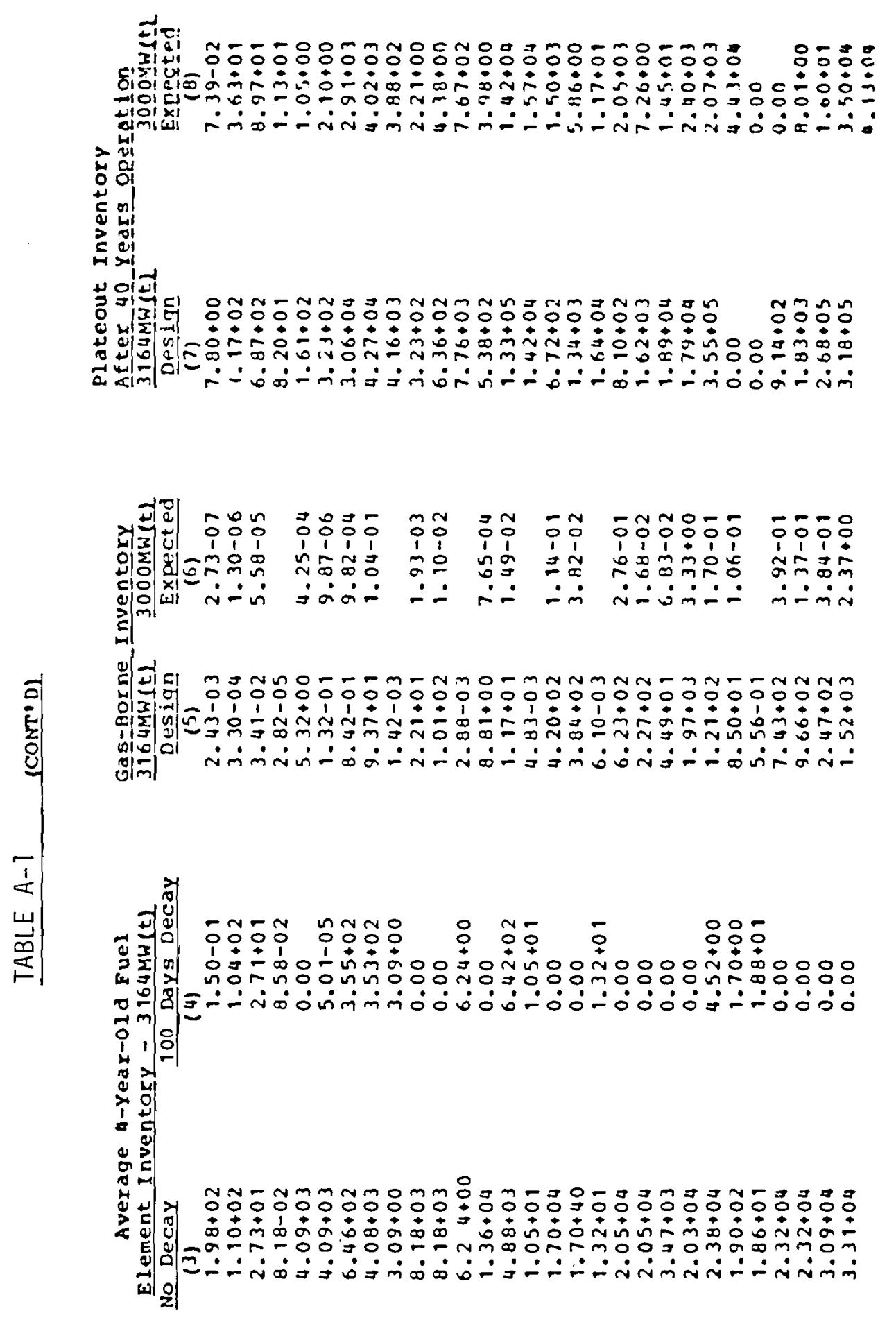

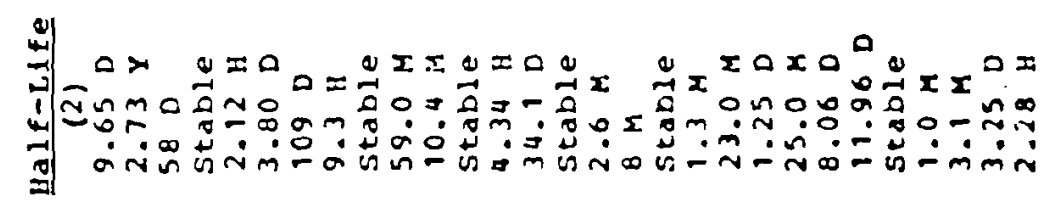

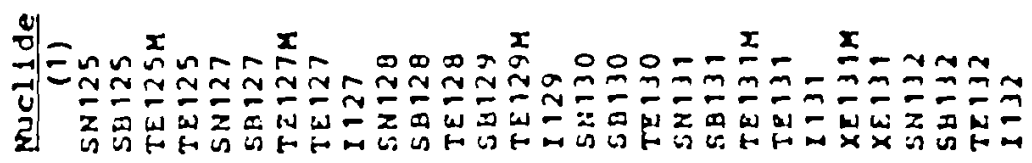




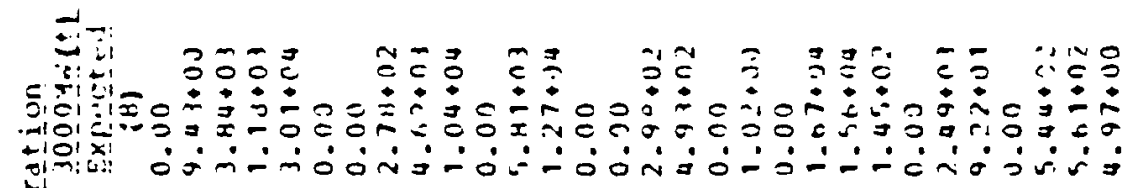

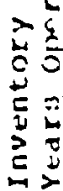

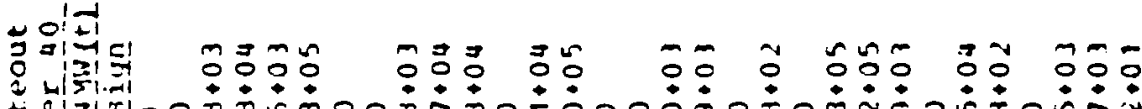

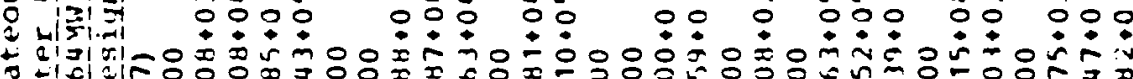

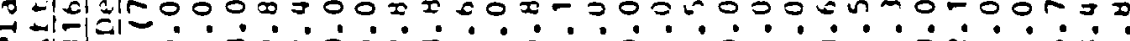

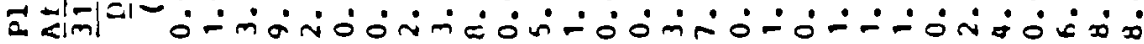

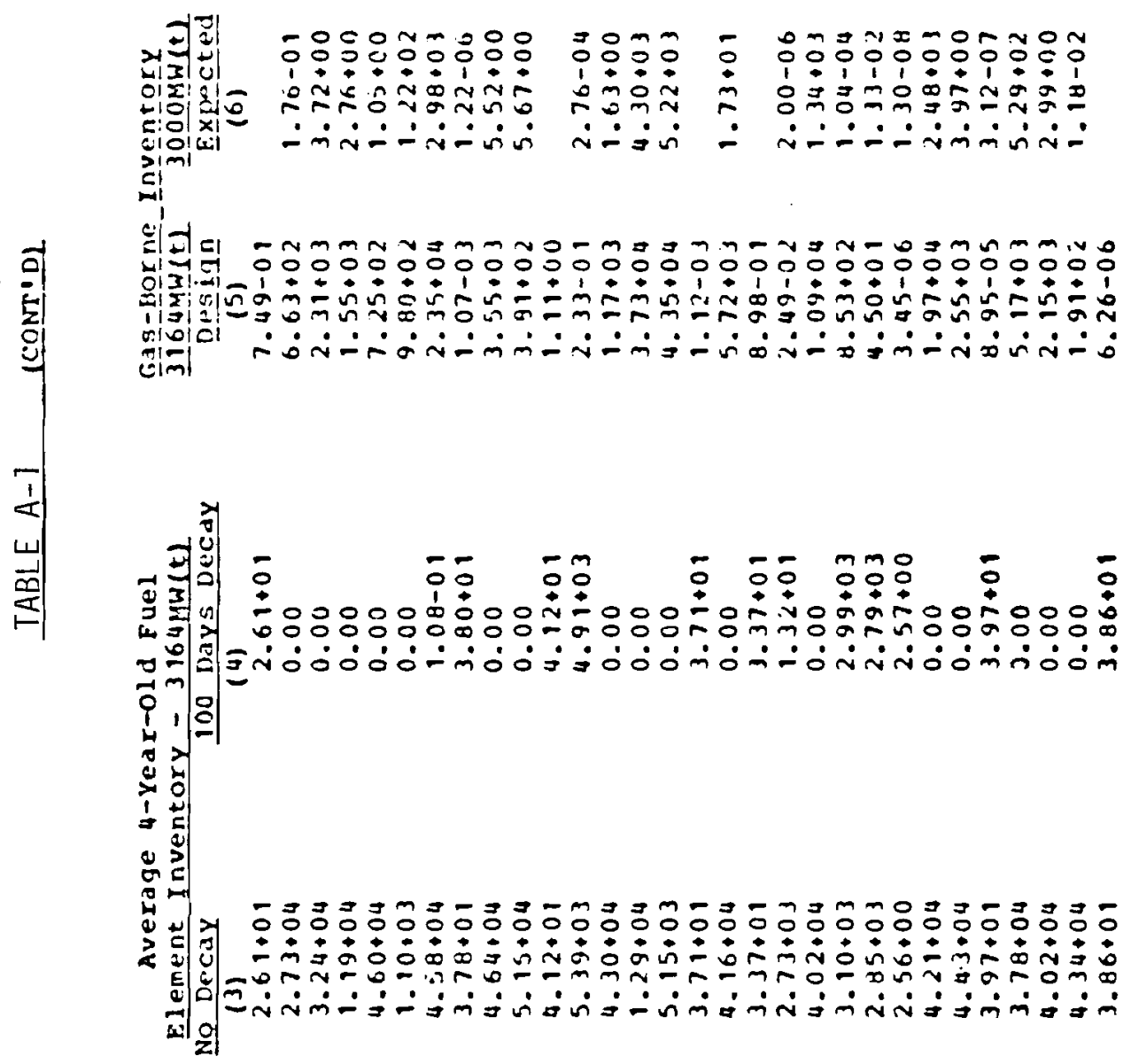

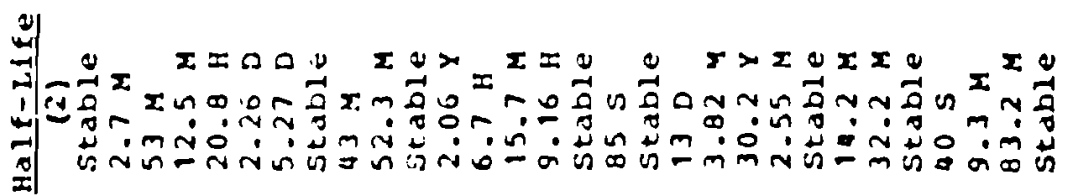

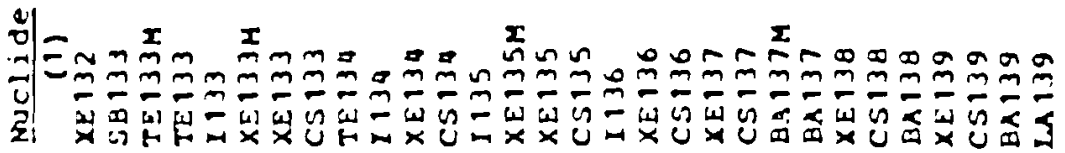



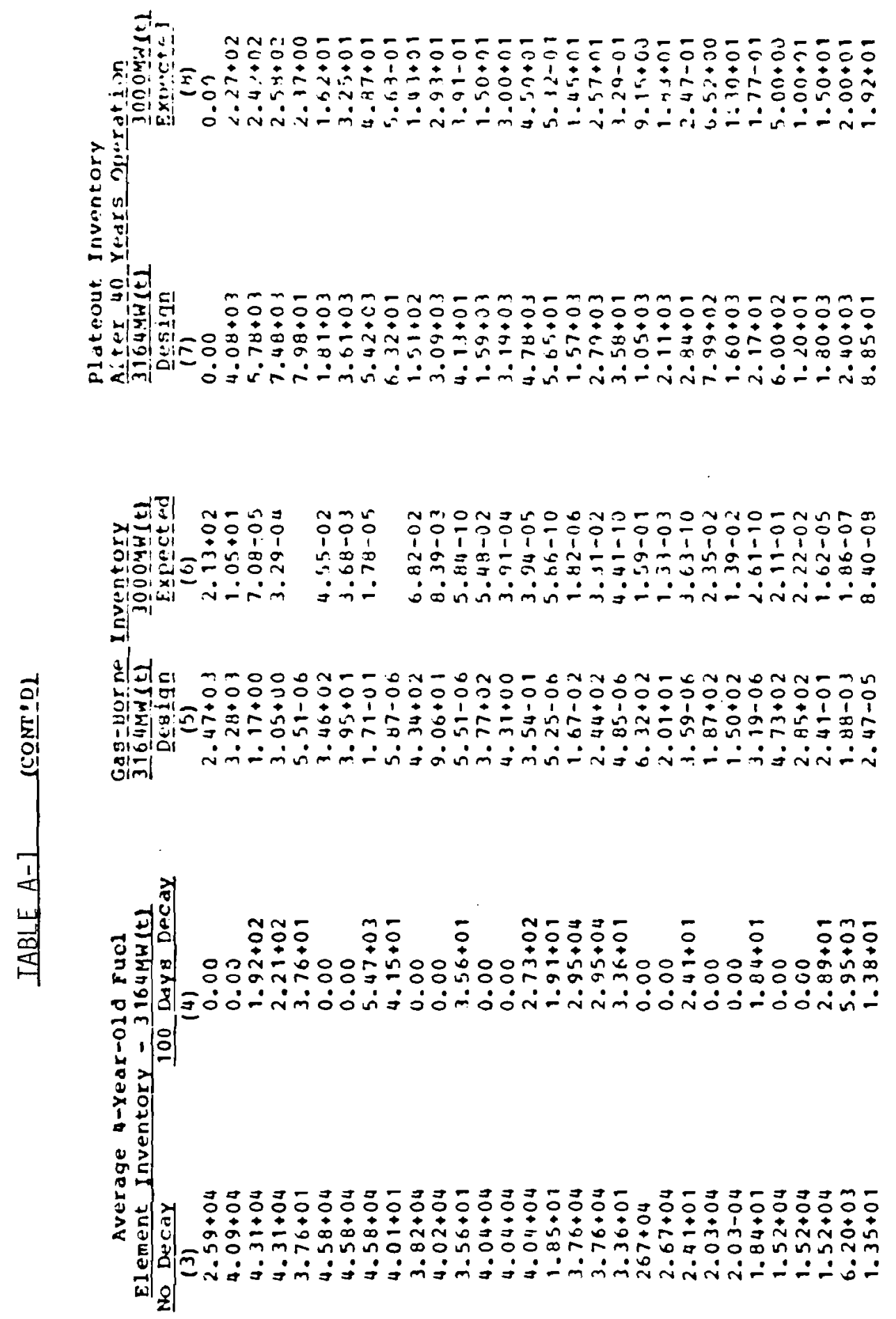

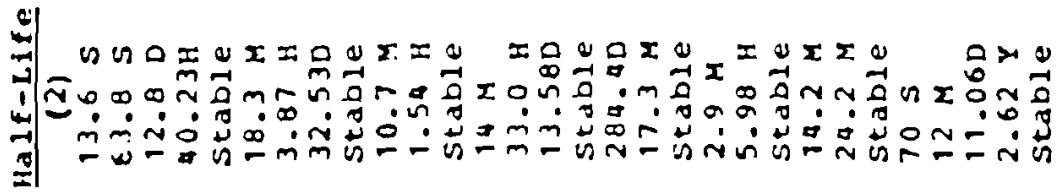

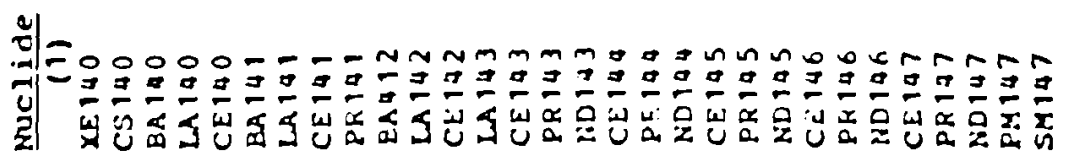



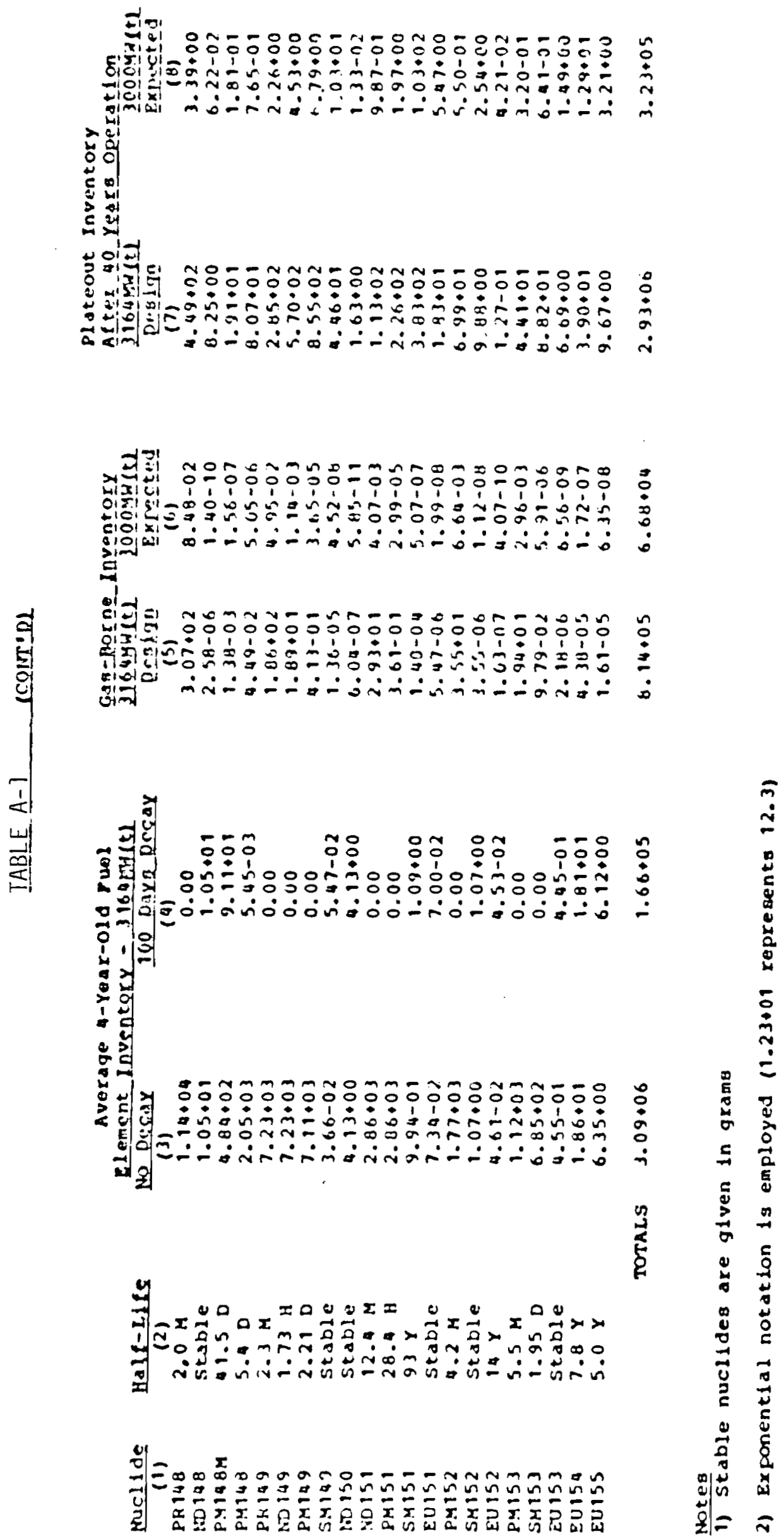
TABLE A-2. REIEASE FRACTIONS

\begin{tabular}{lcc}
\hline & Fission Product & Release Fraction \\
(a) Coolant Inventory & Al1 & 1 \\
(b) Plateout Inventory & Cs & 0.0006 \\
& Sr & 0.007 \\
& Ce & 0.011 \\
& All other Metals & 0.011 \\
(c) Fuel Inventory & I & 0.011 \\
& Particulates & 0.01 \\
& I & 0.25
\end{tabular}


PART I I

TRANSPORT AND DEPOSITION OF IODINE IN THE CONTAINMENT VESSEL

OF A HIGH TEMPERATURE GAS-COOLED REACTOR FOLLOWING A HYPOTHETICAL FISSION PRODUCT RELEASE ACCIDENT

by

A. K. Postma

I. BACKGROUND

A. HTGR Design Considered

While in principle HTGR's may employ a number of inert gases as coolants, and various materials for fuel element cladding, HTGR's of American design use helium as coolant, and graphite for moderator and fuel channels. In the present study, only the HTGR of American design will be considered.

In the U. S. two HTGR installations exist. These are the Peach Bottom and Ft. St. Vrain reactors. Detailed designs have been developed for larger plants: Summit Power Station ${ }^{(3)}$ and Fulton Generating Station ${ }^{(4)}$. For the present study, the Fulton Plant was taken as the reference plant design.

\section{B. Accident Scenario Considered}

The accident scenario is a hypothetical one for HTGR's which is related to those currently described for light water reactors (LWR's) $(1,2)$. It is assumed that failure of a PCRV (prestressed concrete reactor vessel) closure permits pressurized helium to flow from the PCRV to the containment vessel, carrying with it a fraction of the iodine deposited in the primary coolant circuit. No credit is taken for emergency core cooling, and the fuel is assumed to heat to the failure point by fission product decay energy. When fuel failure occurs, it is assumed that the noble gases escape and carry along the iodine inventory. Iodine released to the containment atmosphere is assumed to partition among three forms: elemental gas, organic iodides, and particulate-associated iodine. These three iodine forms are then depleted from the gas phase by plate-out, fallout, and operation of air cleaning systems. 
This scenario for iodine behavior is similar to the MHA (maximum hypothetical accident) described by Gulf General Atomics Corporation in the GASSAR Report ${ }^{(5)}$. It is a more severe accident than the DBDA (design basis depressurization accident) considered in the Fulton PSAR $^{(4)}$. No consideration was given to melt-through or other modes of containment failure because such events are not included in existing Regulatory Guides 1.3 and $1.4^{(1,2)}$, and because the likelihood of a meltthrough does not appear to be higher for HTGR's than for LWR's. This choice of source term is consistent with those defined for LWR's which incorporate required conservatisms and the NRC defense-in-depth philosophy.

One physical feature of HTGR's which alters the accident scenario as compared to LWR's is the massive graphite core. Due to the large thermal inertia of the graphite mass, heat-up by decay energy would be much slower than that predicted for LWR cores. The effect is a significant delay in the iodine release from the core.

\section{POSTULATED IODINE SOURCE TERM TO CONTAINMENT}

\section{A. Iodine Release From Fuel}

In order to estimate the possible iodine concentration in containment the conservative estimate made by NRC's Accident Analysis Branch ${ }^{(7)}$, as shown in Table I, was used.

Table I. Assuried Iodine Source Terms to Containment For Postulated MHFPR Accident

\begin{tabular}{|c|c|c|}
\hline $\begin{array}{l}\text { Release } \\
\quad \text { No. } \\
\end{array}$ & $\begin{array}{l}\text { Time } \\
\text { Hours }\end{array}$ & $\begin{array}{c}\text { Fraction of Core } \\
\text { Inventory }\end{array}$ \\
\hline 1 & 0 & 0.01 \\
\hline 2 & 1 & 0.20 \\
\hline 3 & 2 & 0.29 \\
\hline & & 0.50 \\
\hline
\end{tabular}


Due to the high temperatures involved, iodine released from the primary system would be expected to be present as the elemental gas, or as solid aerosol particles such as CSI. Experimental evidence indicates that $I_{2}$ will predominate ${ }^{(8)}$, and it is assumed that iodine released to the containment atmosphere is initially present as $\mathrm{I}_{2}$. Once in the containment vessel iodine may be converted to organic iodides and become associated with aerosol particles.

Postma, et a1. ${ }^{(9)}$ studied available information on organic iodide formation under HTGR accident conditions. They identified two paths to organic iodide formation: non-radiolytic and radiolytic formation. It was found that the fractional conversion to organic forms was dependent on the iodine concentration and on the amount of oxygen in the containment gas phase.

The iodine concentration resulting from the $50 \%$ core inventory source will be about $100 \mathrm{mg} / \mathrm{M}^{3}$, the value typical for the large loss-ofcoolant accidents postulated in LWR's. The concentrations are similar because core power levels, fractional iodine releases, and containment vessel volumes are similar in magnitude to LWR's. Oxygen content of the containment atmosphere in the HTGR can be reduced by reaction with hot core graphite. However studies of oxygen ingress rate through the failed penetration opening have shown this rate to be slow ${ }^{(5)}$, and for the first several hours the oxygen content of the containment atmosphere would not be significantly depleted. Therefore, air-like concentrations of oxygen wi1l exist in the containment atmosphere.

For a containment atmosphere containing air-like oxygen concentrations, and for an iodine concentration of $100 \mathrm{mg} / \mathrm{m}^{3}$, Postma, et al. projected that non-radiolytic processes could convert no more than $3.2 \%$ of released iodine to organic iodide. Radiolytic conversion was projected to add an additional $6.9 \%$ for a total conversion of $10.1 \%$. For the present study, it is assumed that $10 \%$ of each puff release is present as methyl iodide. This percentage conversion is higher than the $4 \%$ assumed for LWR's, and reflects the higher conversions found experimentally for HTGR atmospheres than were found for LWR accident atmospheres. We should stress that data available for HTGR conditions are few and the conversion percentages are projections based on these few data. It is likely that the fractional conversions could be reduced as new information applicable to HTGR's becomes available. 
Iodine in the containment atmosphere will interact with aerosols present, and a fraction will become particulate-associated iodine. Potential sources of aerosol in the accident atmosphere include: (1) pre-accident aerosols in the containment atmosphere, (2) particles resuspended from surfaces during helium depressurization, and (3) solid fission product aerosols. None of these three potential aerosol sources appears to be capable of producing aerosols of high sorptive capacity, and therefore we see no reason to deviate from the approach taken in LWR's. For LWR's, 5\% of released jodine is assumed to be present as an aerosol $(1,2)$, and this value will be used in the present study.

The iodine source terms, expressed in terms of fractional core inventories for the three assumed releases and the three physicochemical forms are summarized in Table 2 .

Table 2. Summary of Iodine Source Terms to HTGR Containment Atmosphere for Postulated Accident

\begin{tabular}{ccccc}
$\begin{array}{c}\text { Puff } \\
\text { Release } \\
\text { No. }\end{array}$ & $\begin{array}{l}\text { Time of } \\
\text { Release, } \\
\text { Hr. }\end{array}$ & $\begin{array}{l}\text { Elemental } \\
\text { Iodine }\end{array}$ & $\begin{array}{l}\text { Methy } \\
\text { Iodide }\end{array}$ & $\begin{array}{c}\text { Particulate } \\
\text { Iodine }\end{array}$ \\
\cline { 2 - 2 } 1 & 0 & 0.0085 & 0.001 & 0.0005 \\
2 & 1 & 0.17 & 0.02 & 0.01 \\
3 & 2 & $\underline{0.2465}$ & 0.029 & 0.0145 \\
Total & 0.425 & 0.050 & 0.025
\end{tabular}

III. IODINE TRANSPORT IN THE CONTAINMENT VESSEL

A. Description of Conditions in the Containment Atmosphere

The reference design containment vessel is a stee1-1ined pressure vessel having a flat base, cylindrical walls, and a rounded upper dome. Inside this vessel is located the primary reactor vessel. The primary reactor vesse 1 is a large re-enforced concrete structure which contains the primary cooling loop as well as the core itself. Because the primary cooling system is located within the PCRV, the containment vessel is less compartmented than in a typical PWR. The reference HTGR containment system is depicted in Figure 1 . 


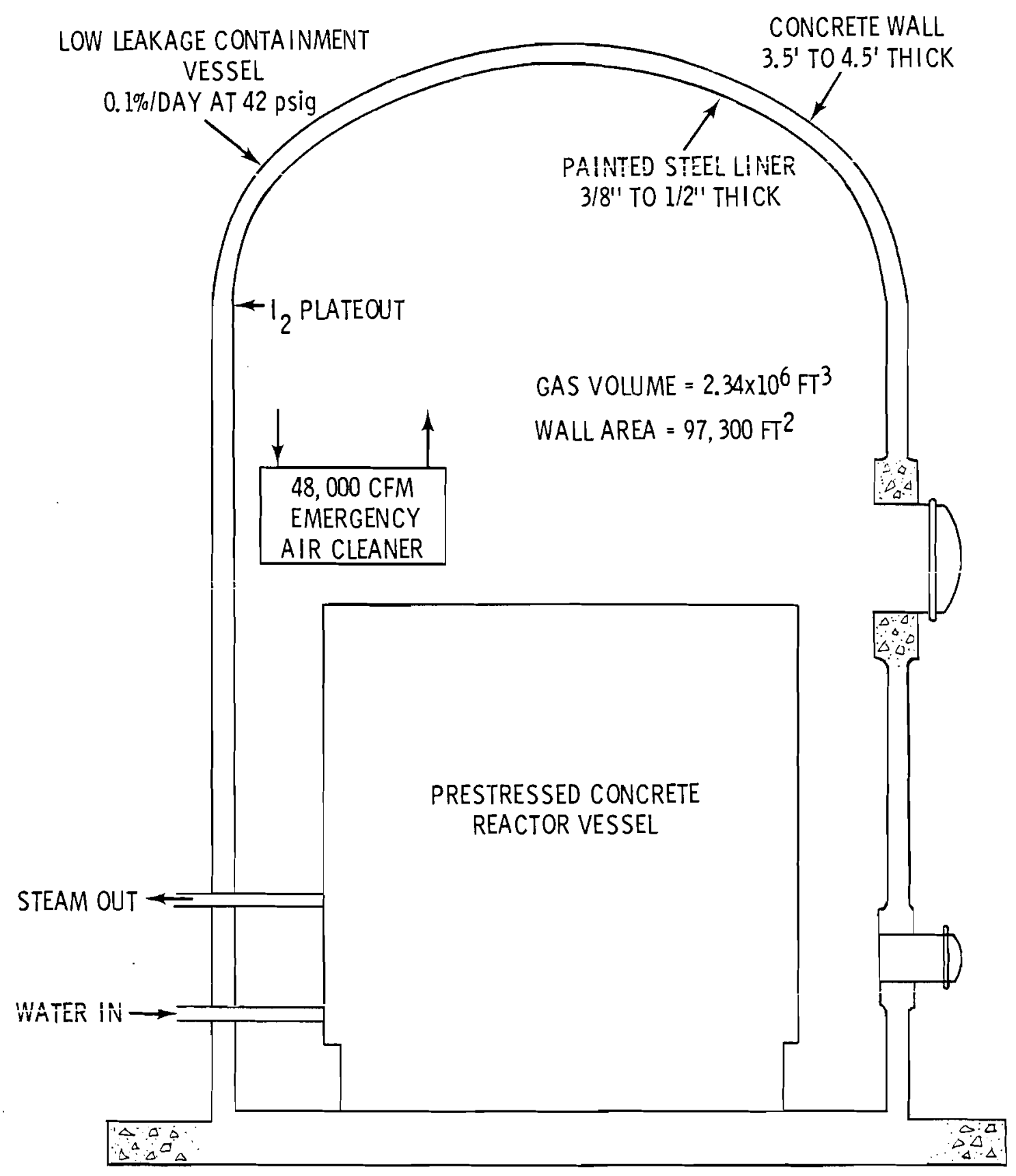

FIGURE 1. Schematic Diagram of Reference HTGR Containment Vesse? 
Active coolers are not employed in the HTGR containment vessel to 1 imit temperature buildup. Such devices are not required because the sensible heat of the helium coolant is absorbed by heat sink masses which comprise the containment system. Time variations of pressure and temperature, as computed for the Fulton Station $(10)$, are shown in Figures 2 and 3.

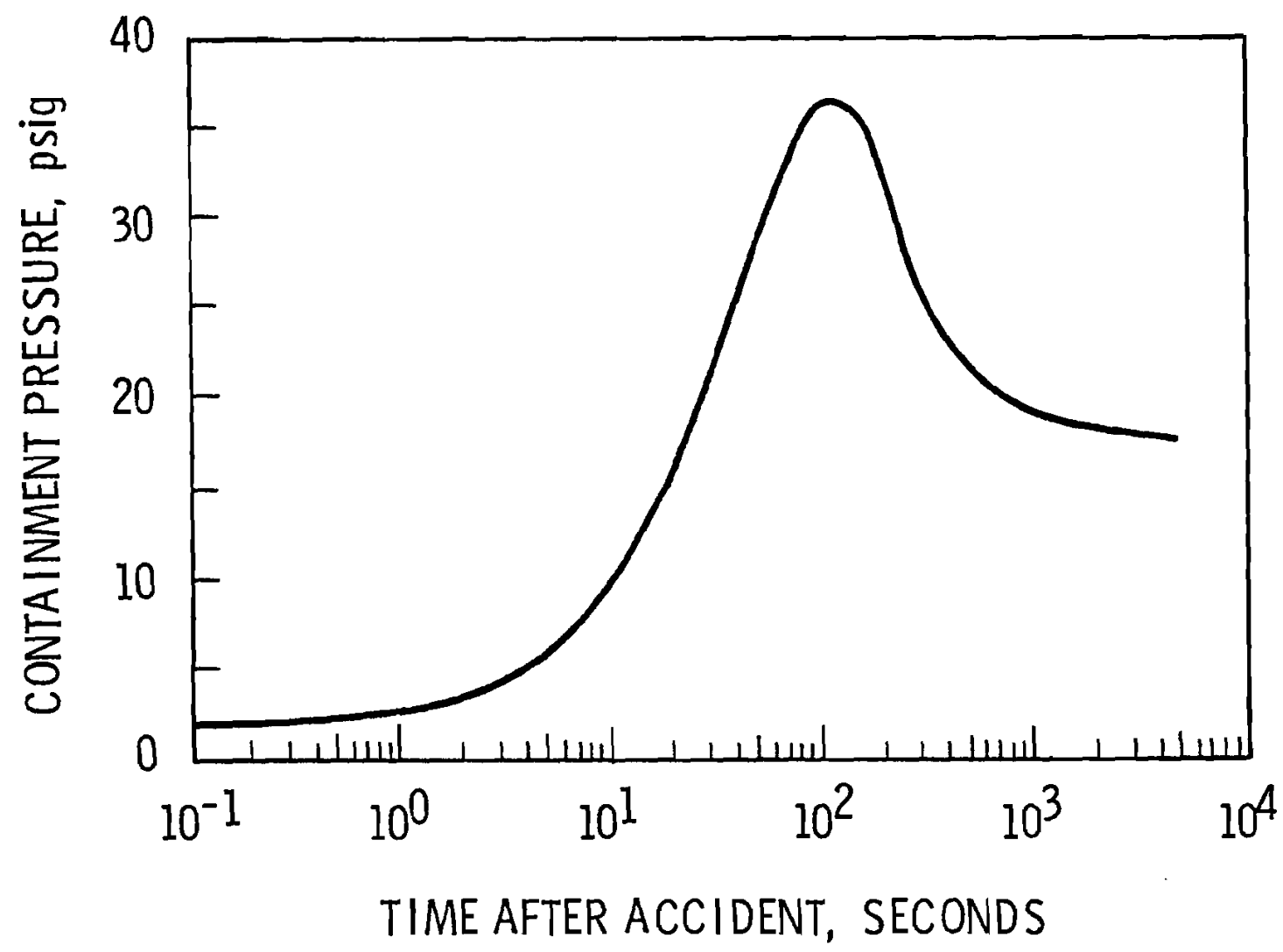

FIGURE 2. Pressure in Containment Vessel Following a Depressurization Accident in The Fulton Station (10) 


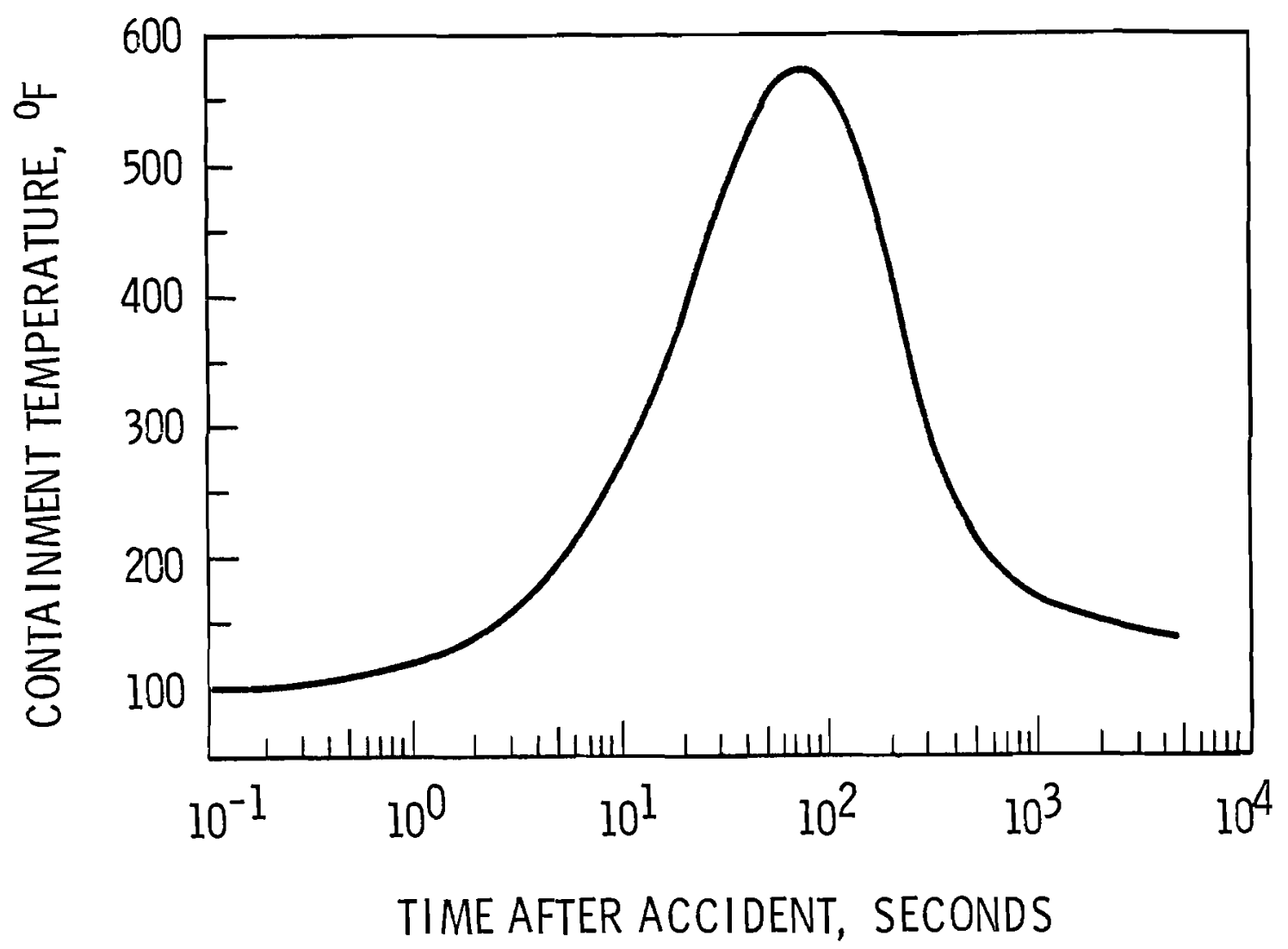

FIGURE 3. Gas Temperature In Containment Vessel Following (9o)
Depressurization Accident In The Fulton Station

The pressure in the containment vessel rises to a peak of 37 psig, and rapidly falls to a steady value of about 18 psig. Thus for the major iodine releases, the gaseous environment will be an air-helium mixture at a total pressure of about 1.25 atmospheres.

Gas temperature increases from $100^{\circ} \mathrm{F}$ to a $570^{\circ} \mathrm{F}$ maximum, and then rapidly falls to less than $150^{\circ} \mathrm{F}$ as heat is transferred to structural heat sinks. The most important iodine releases will thus occur after the gas temperature has fallen back to the $100^{\circ} \mathrm{F}$ to $150^{\circ} \mathrm{F}$ range. 
B. Removal Mechanisms For Iodine

1. Air Cleaning System

The most important atmospheric cleanup mechanisms in the HTGR containment vessel is the emergency air cleaning system. The makeup of one of the three air cleaning loops is depicted in Figure 4.

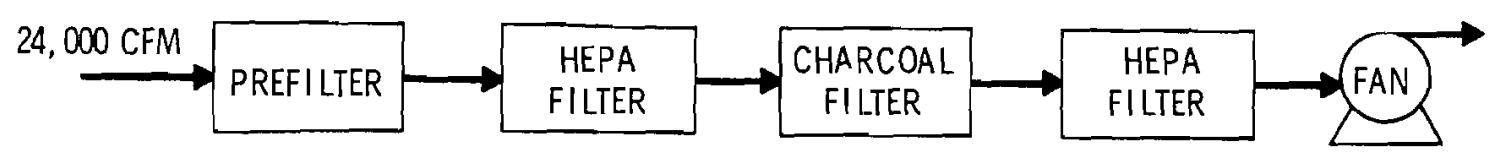

FIGURE 4. Components for Individual Air Cleaning Loops for Reference Containment System

Under accident conditions, only two of the three loops are assumed to operate, yielding a total air cleaning system flow rate of 48,000 cfm.

This air cleaning system design incorporates components which will provide effective performance of the system for the airborne radioactive materials. 
A prefilter is provided to capture the bulk of airborne particle mass, assuring that the HEPA filter does not become plugged. A loading capacity of $41 \mathrm{~b}$ per filter for each of 24 filters per loop provides a dust holding capacity of $4(24)(2)=1821 \mathrm{~b}$ for the 48,000 cfm system.

The first HEPA filter efficiently removes aerosols which penetrate the prefilter, thus protecting the charcoal filter. The charcoal filter sorbs elemental iodine and organic iodides. The final HEPA filter is provided to retain any contaminated charcoal dust entrained from the charcoal filter.

The air cleaning system design provided in the reference containment system is in accordance with requirements out 1 ined in Regulatory Guide $1.52(11)$. Because the containment atmosphere conditions of temperature and relative humidity are moderate, a removal efficiency of $99 \%$ is assumed for elemental iodine, $95 \%$ for methyl iodide, and $99 \%$ for particles.

The jodine removal rate resulting from operation of the air cleaning system is given by:

$$
\text { removal rate }=\text { FCE }
$$

where $F=$ flow rate,

$C=$ iodine gas phase concentration, and

$E$ = iodine removal efficiency.

If only the air cleaning system caused removal, and if no iodine sources were present, the concentration in the containment vessel would decay exponentially:

$$
c=c_{0} \exp -\frac{F E}{V} t
$$

$$
\text { where } \begin{aligned}
C & =\text { concentration at time } t, \\
C_{0} & =\text { concentration at time zero, } \\
F & =\text { flow rate, } \\
E & =\text { fractional removal efficiency, and } \\
V & =\text { volume of containment gas space. }
\end{aligned}
$$


Since the assumed $E$ values are $0.99,0.99$, and 0.95 for elemental, particulate, and organic iodides respectively, all iodine forms will be removed with substantially the same rate constant.

\section{Surface Deposition of Elemental Iodine}

Elementa 1 iodine is sorbed by many surfaces as shown by numerous studies. Deposition of elemental iodine onto containment surfaces under accident conditions in LWR's was reviewed by Postma, et al. (13) who concluded that the removal rate early in the accident was limited by gas phase mass transfer resistance.

The prime difference between the LWR and HTGR environment, as regards surface deposition rate, is the absence of condensing steam in the HTGR. The condensing steam causes several effects. on the one hand, condensing steam greatly increases the heat transfer coefficient, and thereby minimizes the temperature difference in the gas phase along the containment wal1. Since the gas phase mass transfer rate increases with the temperature difference, the enhanced heat transfer caused by the condensing steam leads to lower gas phase mass transfer coefficients. The water layer formed by condensed steam on the wall represents a diffusional resistance between airborne iodine and the painted wall surface. Acting to aid iodine deposition, however, is the sorptive capacity of the water film. The water film would aid deposition if the wall surface itself were passive to jodine.

After reviewing all available experimental data on iodine deposition on surfaces in containment vessels, Postma, et a1. (12) concluded that ".... the initial deposition proceeds at a rate 1 imited by gas phase mass transfer, and that after the concentration decays by a factor of 100 or so, the removal rate slows. There is no evidence that the properties of the surface limit the initial deposition rate. Nor is there evidence that the sweep effect of condensing steam is controlling. Therefore, the ability to predict iodine deposition under accident conditions depends primarily on 
ones ability to predict gas phase mass transfer coefficients under accident conditions." Since the constructional features of the HTGR containment vessel are similar to those employed in PWR's, this conclusion applies to the HTGR as well.

As described in reference (12), the Knudsen-Hilliard model of iodine deposition (13) provides a simple method for predicting the wall deposition rate. It is based on a heat transfer - mass transfer anology. For laminar flow of gas along a wall, the mass transfer coefficient is

$$
\frac{K 1}{D}=0.59(\mathrm{GrSc})^{1 / 4}
$$

and for turbulent flow

$$
\frac{k 1}{D}=0.13(\mathrm{GrSc})^{1 / 3}
$$

$$
\text { where } \begin{aligned}
k & =\text { mass transfer coefficient, } \\
1 & =\text { length measured along surface, } \\
D & =\text { diffusivity of iodine, } \\
\mathrm{Gr} & =\text { Grashov number }, \text { and } \\
\mathrm{SC} & =\text { Schmidt number. }
\end{aligned}
$$

These two equations allow a mass transfer coefficient to be calculated once the temperature difference at the wall is known. For typical LOCA conditions, Hilliard and Coleman ${ }^{(14)}$ quote a distance of $10 \mathrm{ft}$ for the transition from laminar to turbulent flow. Calculated mass transfer coefficients based on Equation (4), as made by Knudsen and Hilliard ${ }^{(13)}$ are presented in Figure 5 . While the curves shown apply to steam-air mixtures, the properties of the gas are not critical, and similar curves would apply for the HTGR a tmosphere. The critical parameter is the inside temperature difference, which wi11 tend to be higher for HTGR atmospheres than for the steam-air atmospheres of LWR's. 


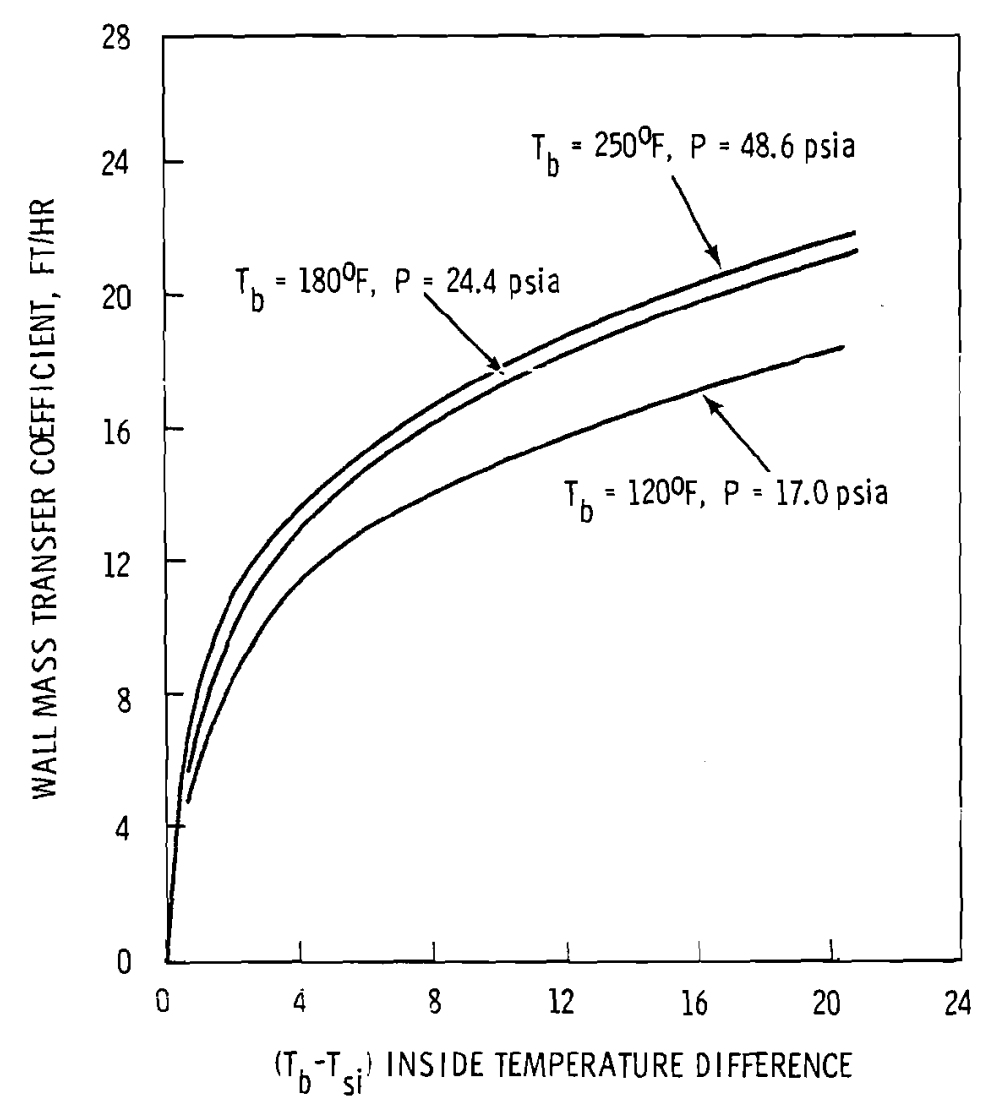

FIGURE 5. Mass Transfer Coefficients As a Function of Inside Temperature Difference for Steam-Air Atmospheres (13)

A temperature difference on the inside wa 11 will be caused by the thermal transient associated with the depressurization. However, this transient is largely over by the time the iodine reaches the containment vessel. A longer term heat source is decay heat of fission products in the containment atmosphere, and an inside temperature difference was estimated for the halogen decay energy. Based on series heat transfer through the containment wall, including gas films inside and outside, the steady state transfer of $200 \mathrm{BTU} / \mathrm{sec}$ leads to an inside $\Delta T$ of about $7^{\circ} \mathrm{F}$. The heat generation rate is that due to $50 \%$ of core halogens $(16)$. From Figure 5 , a mass transfer coefficient for elemental iodine of about $13 \mathrm{ft} / \mathrm{hr}$ 
$(0.11 \mathrm{~cm} / \mathrm{sec})$ is predicted. This value is close to an upper limit value of $0.14 \mathrm{~cm} / \mathrm{sec}$ recormended by Postma, et a1. (12).

The initial plateout rate is given by:

$$
\text { plateout } \lambda=\frac{K A}{V}
$$

where $k=$ wa11 mass transfer coefficient,

$A=$ surface area of wa 11 , and

$V=$ volume of gas space.

Using a mass transfer coefficient of $13 \mathrm{ft} / \mathrm{hr}$, a wall surface area of $9.7 \times 10^{4} \mathrm{ft}^{2}$, and a gas volume of $2.3 \times 10^{6} \mathrm{ft}^{3}$, one calculates a plateout $\lambda$ of $0.55 \mathrm{hr}^{-1}$.

The initial wall plateout rate will not continue indefinitely but will slow after the gas phase iodine concentration becomes low. For natural transport alone (no filter operation) the airborne decay slows after the concentration falls lower than about $0.5 \%$ of the initial value ${ }^{(14)}$. The same effect occurs when a recirculating filter loop is operated. Surface deposited iodine desorbs and becomes an iodine source, slowing the iodine decay rate caused by filter operation.

This approach to equilibrium may be handled in several ways. First and most simply, one may adopt a cut-off concentration, say at $1 \%$ of initial, at which no further removal is computed. The cut-off limit is an approach used in LWR models (16). A second possibility is to treat the plated iodine as reversibly sorbed, and estimate the rate of its evolution. The latter approach will be followed in the present study.

If the paint on the containment wall is considered a sorbent, the rate of iodine desorption may be computed from a material balance on the paint:

$$
\begin{array}{ll}
\text { Iodine Input Rate } & =0 \\
\text { Iodine Output Rate } & =k A\left(C_{g i}-C_{g}\right) \\
\text { Iodine Accumulation Rate } & =v_{p} \frac{d C_{p}}{d t}
\end{array}
$$


Setting input rate equal to output rate plus accumulation rate one gets:

$$
v_{p} \frac{d C_{p}}{d t}=-k A\left(C_{g i}-C g\right)
$$

where

$$
\begin{aligned}
V_{p}= & \text { volume of paint, } \\
C_{p}= & \text { iodine concentration in paint, } \\
k= & \text { wa11 mass transfer coefficient, } \\
A= & \text { wa11 area, } \\
C_{g i}= & \text { iodine concentration in gas phase } \\
C_{g}= & \text { iodine concentration in bulk gas phase. }
\end{aligned}
$$

The maximum desorption rate can be obtained from Equation (6) by setting $C_{g}=0$. If one also sets $C_{g_{i}}=C_{p} / H$, where $H$ is an iodine equilibrium partition coefficient, Equation (6) can be integrated with respect to time to give

$$
\frac{C_{p}}{H}=C_{g i}=\frac{C_{p o}}{H} e^{-\frac{K A}{V_{p} H} t}
$$

Equations (6) and (7) can be used to define a time dependent iodine source which would act to slow the concentration decay caused by the air cleaning system. This source would not apply if no air cleaning system operated, because as equilibrium is approached, $\left(C_{g}-C_{g i}\right)$ tends to zero, and a source term could not develop for natural plateout alone.

If one assumes that equilibrium is reached between the gas phase and the paint in a containment vessel, the quantity $\frac{P}{V}$ can be related to $C_{0} / C$ :

$$
\frac{V_{p} H}{V}=\frac{C_{0}}{C}-1
$$

where $C_{0}=$ initial airborne iodine concentration,

$C=$ airborne iodine concentration at equilibrium, and

$V=$ volume of gas phase. 
From CSE tests $(14), C_{0} / C$ at the break point in the concentration decay curve was found to be about 200. Therefore, for CSE,

$$
\frac{V_{p} H}{V} \cong 200 \text {. }
$$

For larger plants, this ratio would decrease roughly inversely with linear size scale because $V_{p}$ would increase linearly with the surface area. For a $200 \mathrm{ft}$ tall containment vessel, we estimate

$$
\frac{V_{p} H}{V} \cong 200\left(\frac{67}{200}\right)=67 .
$$

An alternative approach to estimating this ratio would be to compute $V_{p}$ and $H$ from known properties of the paint, i.e., based on data such as presented by Rosenburg, et a1. (17).

\section{Agglomeration and Fallout of Particulate Iodine}

Particulate iodine would follow the physical laws described in another section of this report which treats fission product aerosol behavior. The reader is referred to the aerosol behavior section of this report for estimates of aerosol settling and wall deposition.

\section{Model for Iodine Depletion in Containment Vessel}

1. Elemental Iodine

The initial removal rate will be that caused by operation of the filter system and that resulting from surface deposition:

$$
\frac{C}{C_{0}}=e^{-\left(\lambda_{F}+\lambda_{W}\right) t}
$$

where $C_{0}=$ concentration resulting from a puff release,

$C=$ airborne concentration at time $t$,

$\lambda_{F}=\frac{F E}{V}=$ removal constant due to filter operation,

$\lambda_{W}=\frac{k_{g} A}{V}=$ removal constant due to wall deposition. 
As noted earlier, the initial removal rate will continue only until the airborne concentration is reduced to about $1 \%$ of the initial value. At this point the paint will become saturated with respect to the gas phase and the removal rate will slow. A conservative estimate of the effect of paint desorption may be obtained by assuming that all iodine is reversibly sorbed, and that the desorption proceeds at a rate corresponding to that defined by Equation (6) with $C_{g}=0$. For these conservative assumptions, the material balance equation for the airborne iodine becomes

$$
\frac{d C_{g}}{d t}+\frac{F E}{V} C_{g}=\frac{k_{g} A}{V} C_{g i}
$$

The solution to Equation (10), using Equation (7) to define the time variation of $\mathrm{C}_{g i}$, is

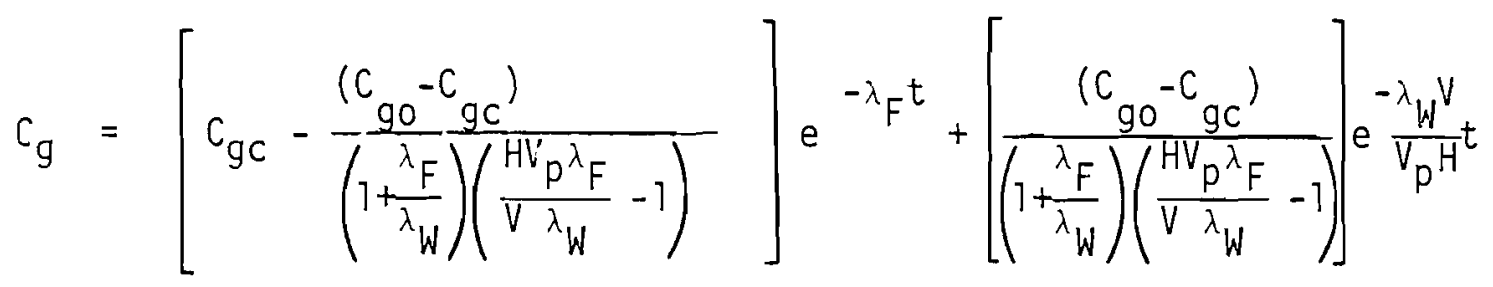

where $\quad C_{g c}=$ cut-off concentration at which wall deposition slows, $t=$ time after cut-off concentration is reached.

The cut-off concentration can be related to the paint properties by Equation (8):

$$
\frac{C_{g C}}{C_{g O}}=\frac{\frac{1}{V H}}{1+\frac{p^{H}}{V}}
$$

Using the value of $\frac{{ }{ }^{H}}{V}$ estimated on the previous page, the value of $C_{g c} / C_{g o}$ is computed to be $1 / 68$ or 0.015 for the reference HTGR plant.

An example calculation has been made for the reference containment system to illustrate the concentration decay predicted by Equations (9) and (11). For the reference plant, the following parameter values were used: 


$$
\begin{aligned}
& \frac{\mathrm{kg}_{\mathrm{g}} \mathrm{V}}{V}=0.55 \mathrm{hr}^{-1} \\
& \frac{\mathrm{FE}}{V}=1.24 \mathrm{hr}^{-1} \\
& C_{g C}=0.015 \mathrm{C}_{g 0} \\
& \frac{H V_{p}}{V}=67
\end{aligned}
$$

The decay in iodine concentration from a single puff release computed from Equations (9) and (11) is portrayed in Figure 6 . As shown, the concentration is predicted to decay rapidly until about $0.2 \%$ of released iodine remains airborne. For longer times, little net removal occurs because the wall desorption rate balances the removal affected by the filter loop.

The iodine depletion predicted by Equations (9) and (11) was compared with experimental results obtained in CSE Test A-13. This particular CSE test was carried out in an air atmosphere at $96^{\circ} \mathrm{F}$, and thus did not involve water films or pools typically associated with LOCA conditions in water reactors. The "dry" conditions reasonably correspond to those for the HTGR containment vessel, and for this reason this CSE test is considered applicable to the reference HTGR plant. For CSE Test A-13, iodine deposition was by surface deposition alone for the first 32 minutes, and then a $1000 \mathrm{cfm}$ filter loop, much like the one pictured in Figure 4, was turned on. The observed natural plateout rate corresponded to a $\lambda_{W}$ of $1.6 \mathrm{hr}^{-1}$. The loop flow of $1000 \mathrm{cfm}$ leads to a predicted $\lambda_{F}$ of $2.28 \mathrm{hr}^{-1}$. The cut-off concentration was chosen as $0.005 C_{0}$ as described earlier in this report. Calculated and measured concentration histories are compared in Figure 7.

As shown by the data in Figure 7 , the model agrees we 11 with the measured concentrations until the concentration falls below the cut-off level of $0.005 \mathrm{C}_{0}$. For longer times, the model overpredicts the airborne concentration. This overprediction is on 


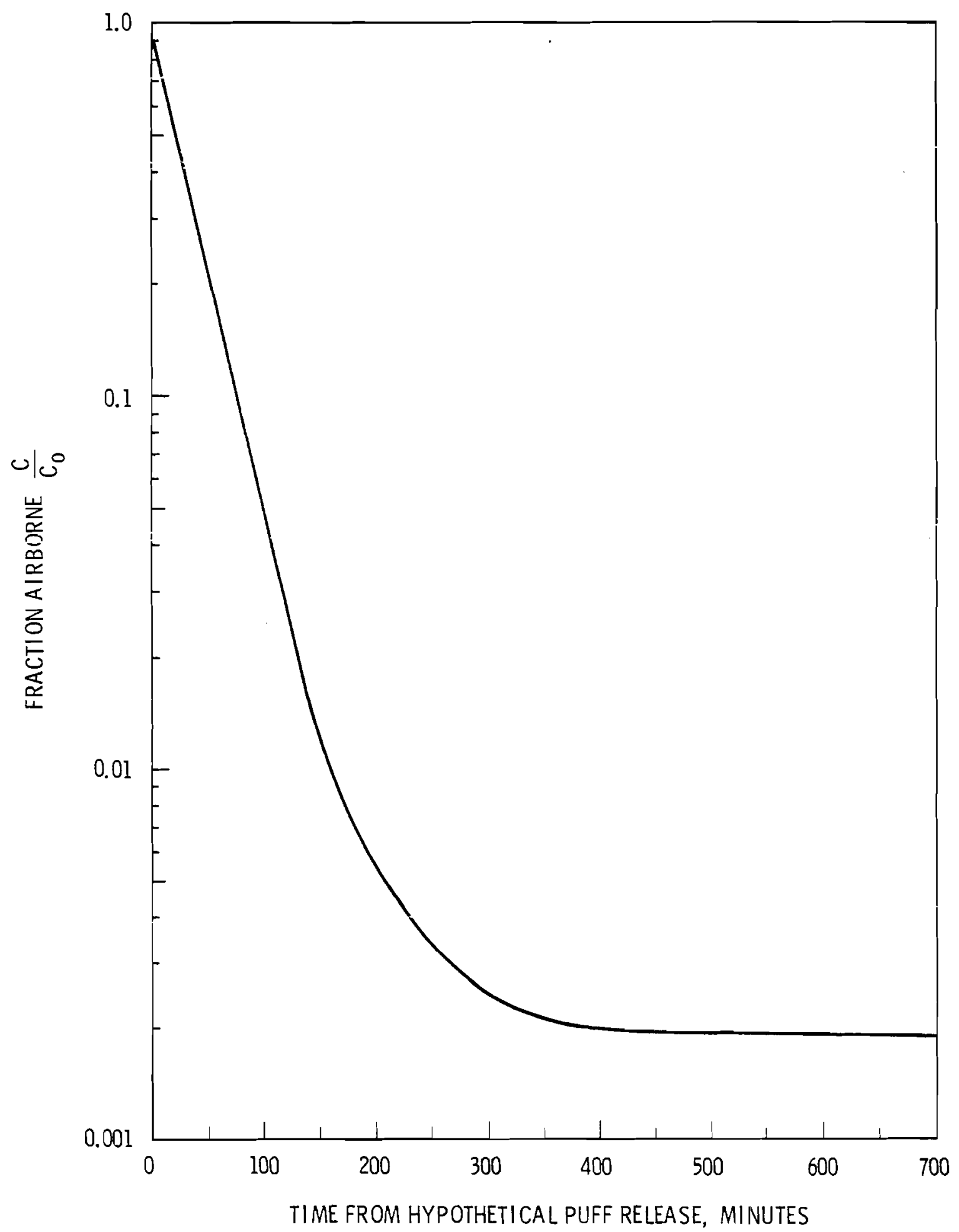

FIGURE 6. Airborne Iodine Depletion by Filter Loop and Natural Plateout in Reference HTGR Containment 


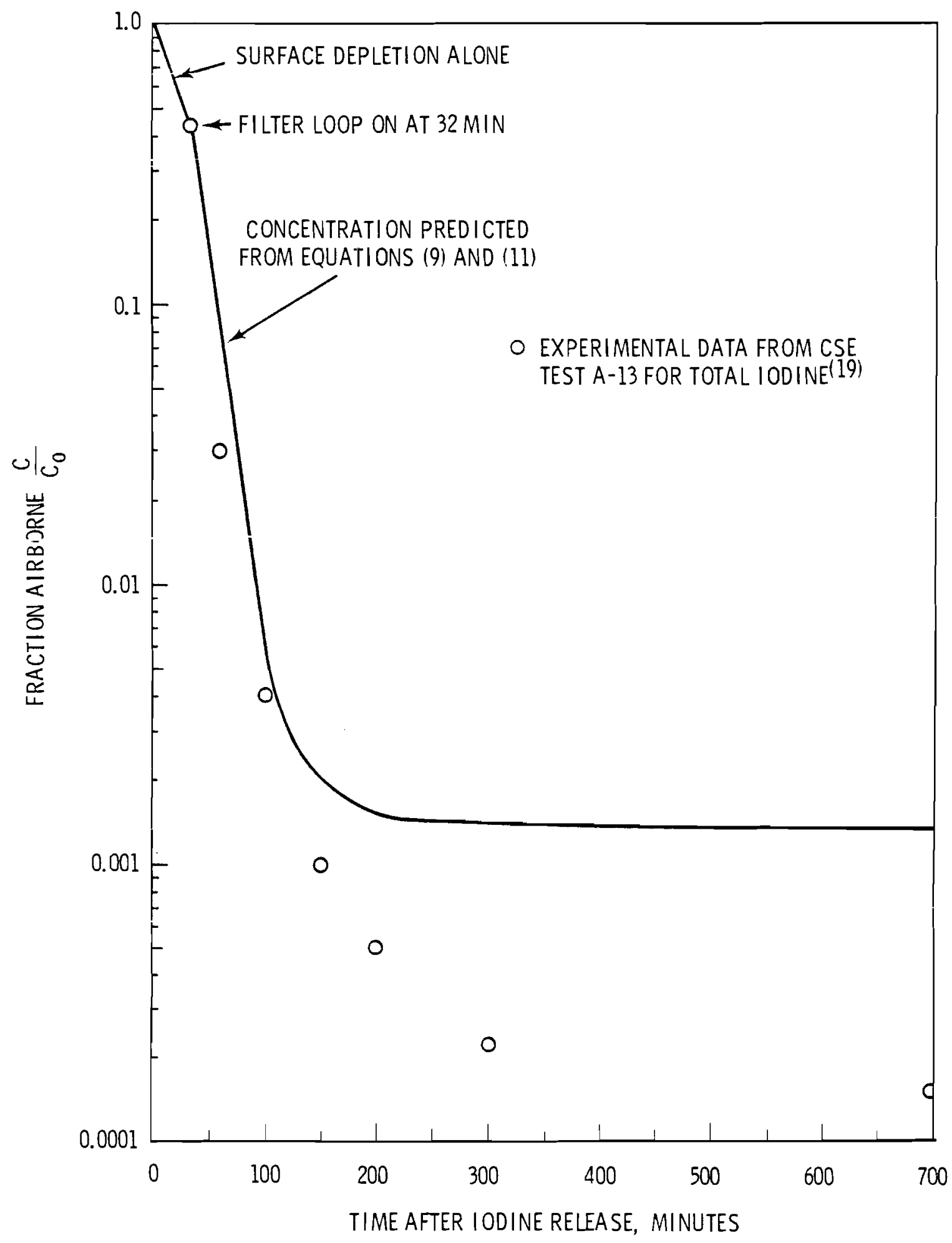

FIGURE 7. Comparison of Model with CSE Test A-13 
the conservative side, and results because the paint sorption was assumed to be fully reversible. In truth, the paint retains a significant fraction of the iodine irreversibly.

\section{Methyl Iodide Removal}

Methyl iodide is not removed to a significant extent by containment surfaces, hence the removal rate constant wi11 be:

$$
{ }^{\lambda} \mathrm{CH}_{3} \mathrm{I}=\frac{\mathrm{FE}}{\mathrm{V}}=\frac{(48,000)(0.95)(60)}{2.3 \times 10^{6}}=1.19 \mathrm{hr}^{-1}
$$

Thus the $\mathrm{CH}_{3} \mathrm{I}$ will decay exponentially until a cut-off concentration is reached. In order to account for potential sources of methy 1 iodide, it is assumed that the methyl iodide concentration fal is exponentially until $C / C_{0}=0.01$, and that no further removal occurs.

\section{Particulate Iodine Removal}

Particulate iodine would be removed by the filter loop as well as by wall deposition and gravity settling. The latter two mechanisms are treated in another section of this report and will not be analyzed here. Removal by the filter loop will be with a rate constant of:

$$
\lambda_{F}=\frac{F E}{V}=\frac{(48,000)(0.99)(60)}{2.3 \times 10^{6}}=1.24 \mathrm{hr}^{-1}
$$

In iodine computations that follow, it was assumed that the particulate iodine concentration decayed exponentially until $C / C_{0}=0.01$, and that no further removal occurred for longer times.

\section{Total Airborne Iodine}

Based on the iodine source terms assumed in this report and on the removal models described, the total airborne iodine inventory was computed. Results are shown in Figure 8 . The spikes in concentration result from the assumed puff release source terms at 0,60 , 


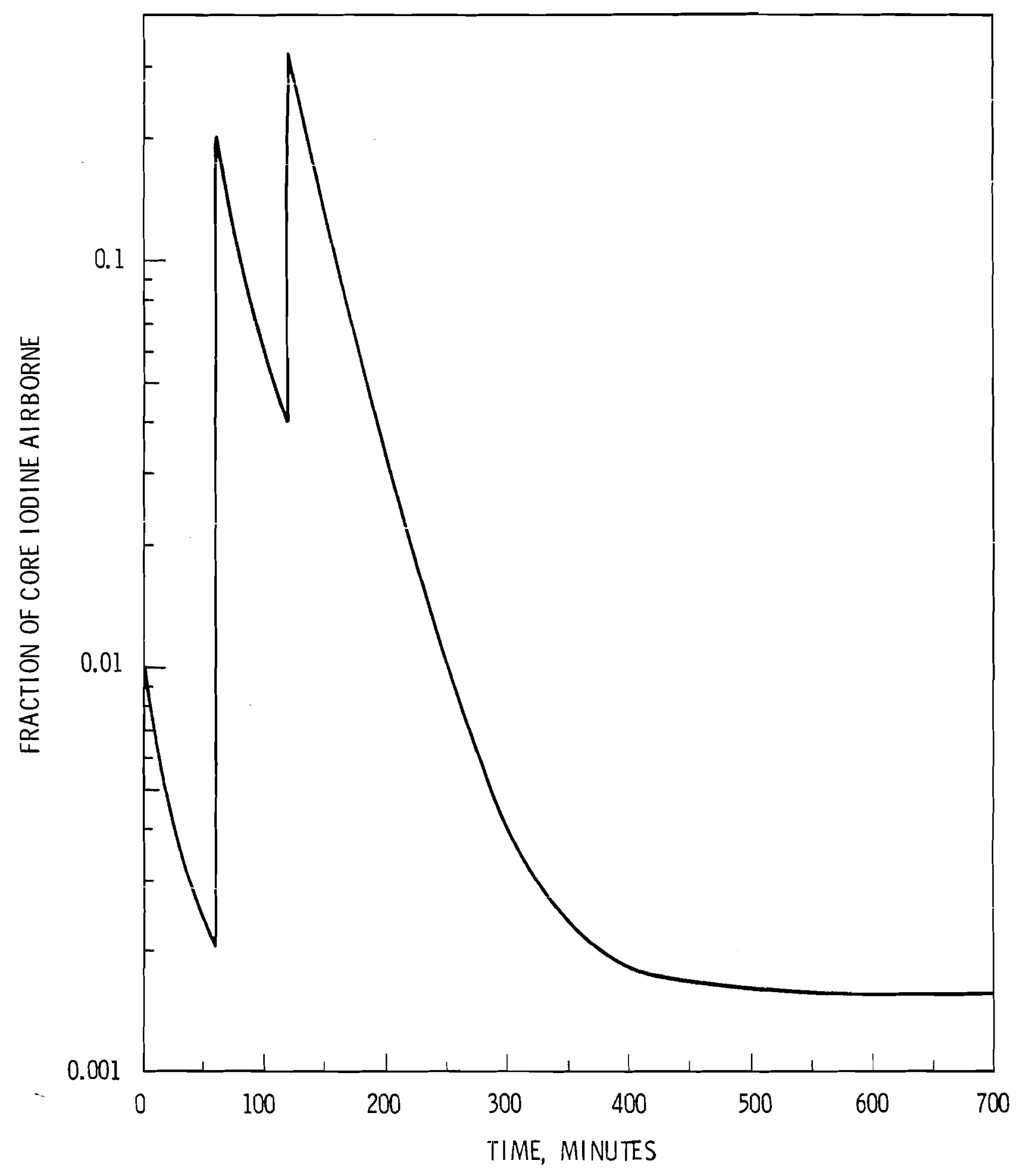

FIGURE 8 . Total Iodine Airborne Predicted for Reference HTGR Containment 
and 120 minutes. The minimum concentration approached at times beyond 500 minutes is due both to the reversible sorption of elemental iodine and to the cut-off concentrations of $1 \%$ used for methyl iodide and particles.

\section{ALTERNATIVE EMERGENCY AIR CLEANING SYSTEMS FOR HTGR PLANTS}

\section{A. Scope of Present Survey}

The present study is focused on a reference plant design (the Fulton Station (4), which uses a single low leakage containment vessel surrounding the PCRV. A recirculating filter loop is provided within the containment vessel to remove airborne fission products, and thereby reduce the atmospheric leakage source term. In this brief review of Emergency Air Cleaning Systems (EACS), we will consider only methods for removing airborne iodine from the containment vessel atmosphere.

Other types of containment systems impose different requirements on an EACS. For example, in a containment-confinement containment system, the reactor vessel is enclosed within a relatively sma11, moderate leakage, high pressure, containment barrier. This relatively small containment vessel is enclosed within a confinement building of standard construction. An EACS is provided to exhaust air from the confinement building at a rate high enough to assure that al1 leakage to the atmosphere is through the EACS. For this system, a highly efficient EACS is desirable because the calculated airborne dose downwind varies 1 inearly with the penetration of the EACS. The required flow rate is determined by the leak-tightness of the confinement building and has little influence on dose calculations. This example is cited to point out that EACS requirements are highly dependent on the type of containment system employed, and hence that an EACS evaluation is specific to a particular containment system design. Hilliard, et al. (19) have evaluated air cleaning system concepts applicable to LMFBR plants; the present survey borrowed heavily from Hilliard's report ${ }^{(19)}$. 


\section{B. Candidate Systems Considered}

Two types of systems can be considered: recirculating, and direct application. In a recirculating system, the contaminated air is pumped through a cleanup device, and then back to the containment atmosphere. Large air flows are required to obtain appreciable dose reduction factors from recirculating systems. In the direct application systems, the cleaning agent is transmitted through the containment atmosphere. Spray systems used in PWR's represent an important example of direct application systems. Direct application systems generally yield much higher dose reduction factors than recirculating systems.

Recirculating systems considered in the present report include filter/adsorbers and aqueous scrubbers. Direct application systems considered included aqueous sprays and a charcoal powder discharge system.

\section{Discussion of Candidate Systems}

\section{Recirculating Filter/Charcoal Adsorber System}

This system design is the one included in the reference plant design. Also, filter/charcoal adsorber systems have been extensively used in water reactors $(20)$ and a regulatory guide prepared for the design of such systems $(11)$.

Based on the evaluation study of Hilliard ${ }^{(19)}$, the advantages of such a system include the following.

- Feasibility is proven by widespread application.

- All forms of iodine can be removed.

- Little additional research is needed to provide a reliable design.

- Inspection and testing of the system are possible.

- Reliability for accident situations is high. 
Disadvantages of a recirculating filter/adsorber include:

- The system is relatively slow acting.

- The system is quite large and costly.

\section{Recirculating Aqueous Scrubber System}

In a scrubber system the filters and charcoal adsorbers would be replaced by an aqueous scrubber. While scrubbers have been used extensively in industrial air pollution control systems, they have not yet found much use in power reactors. Methyl iodide removal in an aqueous scrubber would probably be poor.

Advantages of a scrubber system, compared to a filter/ adsorber, include:

- Smaller equipment could be used.

- Costs would be lower.

Disadvantages of a scrubber include:

- Appreciable research and development would be needed to obtain a proven design.

- Methyl iodide removal efficiency would likely be low.

- Equipment is more complex, making reliable operations more of a problem.

\section{Direct Acting Spray System}

An aqueous spray system installed in the containment vessel could be employed to remove iodine much like those used in pressurized water reactors. Use of a spray system would require installation of a sump, and a means for assuring that liquid water was not introduced into the core. Any water which came into contact with the hot core graphite would contribute to formation of carbon monoxide, which represents a potential explosion hazard. Since presently used spray solutions are not effective in removing methyl iodide, one may assume that methyl iodide would not be removed by the spray system. 
Advantages of an aqueous spray system include the following:

- Rapid removal of elemental iodine could be achieved, leading to DRF values equal to those achieved by PWR spray systems.

- Spray system effectiveness for iodine has been proven in LWR's.

- Low cost.

Disadvantages of a spray system for HTGR application include the following:

- Methyl iodide would not be removed.

- Introduction of large quantities of water into the contairment vessel would pose safety problems which would require extensive study before feasibility could be proven.

\section{Direct Acting Powder Dispersal System}

This system is similar to the spray system, but uses charcoal powder to sorb iodine. The powder would be stored in containers placed high in the containment vessel, and the contents would be discharged following a depressurization accident. While this system is theoretically capable of effective action, it possesses several short-comings. First, no such system has been applied on a large scale, and much development work would be required to prove its practicality. Second, there is no feasible way to recirculate the powder, and very careful timing of discharge would be required to assure that powder delivery corresponded to the release of iodine from the PCRV.

Advantages of a charcoal powder dispersal system appear to be as follows: 
- Rapid removal of elemental iodine and methyl iodide could be achieved.

- System cost is comparatively low.

- Water would not be added to the containment vessel.

Disadvantages of a charcoal powder scrubber system include the following:

- The system is only a concept, and a large development effort would be required to achieve a reliable design.

- Continuous operation would not be possible because the powder could not be recirculated.

- Inadvertent operation of the system would result in a large cleanup cost. 
v. LITERATURE CITED

1. Regulatory Guide 1.3, Revision 2, "Assumptions Used for Evaluating the Potential Radiological Consequences of a Loss of Coolant Accident for Boiling Water Reactors", USAEC Directorate of Regulatory Standards, June 1974.

2. Regulatory Guide 1.4, Revision 2, "Assumptions Used for Evaluating the Potential Radiological Consequences of a Loss of Coolant Accident for Pressurized Water Reactors", USAEC Directorate of Regulatory Standards, June 1974.

3. Preliminary Safety Analysis Report for Summit Power Station, Delmarva Power and Light Company, Wilmington, Delaware.

4. Preliminary Safety Analysis Report for Fulton Generating Station, Philadelphia Electric Company, Philadelphia, Pennsylvania.

5. Genera 1 Atomics Standard Safety Analys is Report, USAEC Docket No. STN-505-1-24, General Atomics Corporation, San Diego, California.

6. Preliminary Safety Analys is Report for Fulton Generating Station, Figure 6.2.1-1, Philadelphia Electric Company, Philadelphia, Pennsylvania.

7. B. K. Grimes, "HTGR Fission Product Release Accident Assumptions", Memo to F. Schroeder, U.S. Nuclear Regulatory Commission, Washington, D. C. , February 18, 1975.

8. R. L. Ritzman, et al., "Release of Radioactivity in Reactor Accidents", Appendix VII, WASH-1400 (DRAFT), U.S, Atomic Energy Commission, 1974.

9. A. K. Postma, P. C. Owzarski, and R. W. Zavadoski. "Review of Organic Iodide Formation Under Postulated Accident Conditions In HTGR's", BNWL-B-356, Battelle Pacific Northwest Laboratory, Richland, Washington, 1974.

10. Preliminary Safety Analys is Report for Fulton Generating Station, Figure 6.2.1-2, Philadelphia Electric Company, Philadelphia, Pennsylvania.

11. Regulatory Guide 1.52, "Design, Testing, and Maintenance Criteria for Atmospheric Cleanup System Air Filtration and Adsorption Units of Light Water-Cooled Nuclear Power Plants", Directorate of Regulatory Standards, U.S. Atomic Energy Commission, Washington, D. C., 1973. 
12. A. K. Postma, R. L. Ritzman, J. A. Gieseke and E. W. Schmidt, "Models for Predicting the Removal of Airborne Contaminants by Reactor Containment Sprays", BNWL-B-417, Battelle Pacific Northwest Laboratories, Richland, Washington, 1975.

13. J. G. Knudsen and R. K. Hilliard, "Fission Product Transport by Natural Processes in Containment Vessels", BNWL-943, Battelle Pacific Northwest Laboratories, Richland, Washington, 1969.

14. R. K. Hilliard and L. F. Coleman, "Natural Transport Effects on Fission Product Behavior In The Containment Systems Experiment", BNWL-1457, Battelle Pacific Northwest Laboratories, Richland, Washington, 1970.

15. Preliminary Safety Analysis Report for Fulton Generating Station, Figure 6.2.3-3, Philadelphia Electric Company, Philadelphia, Pennsylvania.

16. A. K. Postma and W. F. Pasedag, "A Review of Mathematical Models for Predicting Spray Removal of Fission Products in Reactor Containment Vesse1s", WASH-1329, U.S. Atomic Energy Commission, Washington, D. C., 1973.

17. H. S. Rosenberg, J. M. Genco, and D. L. Morrison, "Fission Product Deposition and Its Enhancement Under Reactor Accident Conditions: Deposition on Containment-System Surfaces", BMI-1865, Battelle Memorial Institute, Columbus, OH, 1969.

18. J. D. McCormack, R. K. Hilliard, and A. K. Postma. "Removal of Airborne Fission Products by Recirculating Filter systems in The Containment Systems Experiment", BNWL-1587, Battelle Pacific Northwest Laboratories, Richland, Washington, 1971.

19. R. K. Hilliard, J. D. McCormack, and A. K. Postma. "Evaluation of Air Cleaning System Concepts For Emergency Use In LMFBR Plants", HEDL-TME-76-41, Hanford Engineering Development Laboratory, Richland, Washington, 1976.

20. R. W. Zavadoski, et a1. "Engineered Safety Features Air Cleaning Systems For Commercial Light-Water-Cooled Nuclear Power Plants (A Review of Current Design and Construction Practices)", WASH-1234, U.S. Atomic Energy Commission, Washington, D. C., 1974. 
BNWL-2108

CATEGORY NRC-8

\section{DISTRIBUTION}

No. of Copies

OFFSITE

1 ERDA Chicago Patent Group . 9800 South Cass Avenue

Argonne, IL 60439

A. A. Churm

3 Mary Jinks, Chief Central Mail and Files

U.S. Nuclear Regulatory Commission Washington, D. C. 20555

10 NRC Accident Analysis Branch Directorate of Licensing

Washington, D. C. 20545

W. F. Pasedag (10)

27 ERDA.Technical Information Center for NRC-8 Distribution

2 ERDA Technical Information Center

13 Battelle Columbus
J. A. Gieseke (10)
E. W. Schmidt
(1)
P. Baybutt
(1)
H. Jordan
(1)

No. of Copies

ONSITE

1 ERDA Richland Operations Office

Programs Division

27 Battelle-Northwest
D. E. Olesen
L. T. Pedersen
A. K. Postma
D. L. Reid
E. T. Strahsburg
Technical Files
Technical
Publications 